\title{
REVIEW
}

\section{The impact of COVID-19 on and recommendations for breast cancer care: the Singapore experience}

Jack Junjie Chan (D1,2, Yirong Sim²,3,4, Samuel Guan Wei Ow55, Joline Si Jing Lim,6, Grace Kusumawidjaja2,7, Qingyuan Zhuang2,8, Ru Xin Wong2,7, Fuh Yong Wong2,7, Veronique Kiak Mien Tan2,3,4 and Tira Jing Ying Tan 1,2

'Division of Medical Oncology, National Cancer Centre Singapore, Singapore, Singapore 2Oncology Academic Clinical Programme, Duke-NUS Medical School, Singapore, Singapore ${ }^{3}$ Division of Surgery \& Surgical Oncology, National Cancer Centre Singapore, Singapore, Singapore ${ }^{4}$ SingHealth Duke-NUS Breast Centre, Singapore General Hospital, Singapore, Singapore ${ }^{5}$ Department of Haematology-Oncology, National University Cancer Institute, Singapore, Singapore ${ }^{6}$ Yong Loo Lin School of Medicine, National University of Singapore, Singapore, Singapore 7Division of Radiation Oncology, National Cancer Centre Singapore, Singapore, Singapore

${ }^{8}$ Division of Supportive and Palliative Care, National Cancer Centre Singapore, Singapore, Singapore

Correspondence should be addressed to J J Chan: gmscjac@nus.edu.sg

\begin{abstract}
The ensuing COVID-19 pandemic poses unprecedented and daunting challenges to the routine delivery of oncological and supportive care to patients with breast cancer. Considerations include the infective risk of patients who are inherently immunosuppressed from their malignancy and therapies, long-term oncological outcomes from the treatment decisions undertaken during this extraordinary period, and diverted healthcare resources to support a coordinated whole-of-society outbreak response. In this review, we chronicle the repercussions of the COVID-19 outbreak on breast cancer management in Singapore and describe our approach to triaging and prioritising care of breast tumours. We further propose adaptations to established clinical processes and practices across the different specialties involved in breast oncology, with references to the relevant evidence base or expert consensus guidelines. These recommendations have been developed within the unique context of Singapore's public healthcare sector. They can serve as a resource to guide breast cancer management for future contingencies in this city-state, while certain elements therein may be extrapolatable to other medical systems during this global public health emergency.
\end{abstract}

Key Words
- COVID-19
- breast cancer
- surgery
- systemic anti-cancer
treatments
- radiotherapy
- palliative care

\section{Introduction}

A novel infectious disease caused by severe acute respiratory syndrome coronavirus 2 (SARS-CoV-2) and spread through human-to-human transmission first emerged in Wuhan, China, in December 2019 (Zhu et al. 2020). Coronavirus disease 2019 (COVID-19) can manifest as asymptomatic carriage, mild acute respiratory illness or, worse, fulminant pneumonia complicated by acute respiratory distress syndrome. The World Health Organisation (WHO) declared it as a pandemic on 11 March 2020. By 23 April 2020, this contagion has infected more than 2.5 million individuals worldwide, resulting in over 175,000 deaths.
C 2020 Society for Endocrinology Published by Bioscientifica Ltd. Printed in Great Britain 
As one of the first affected countries outside of China, Singapore saw her first imported case on 23 January 2020. Following few local clusters of COVID-19, Singapore elevated the outbreak risk assessment from Yellow to Orange according to its colour-coded Disease Outbreak Response System Condition (DORSCON) framework on 7 February 2020. Adopting a multi-pronged surveillance and containment strategy executed through border control, contact tracing and quarantine measures, this densely populated Southeast Asian island nation initially curbed rapid transmission (Ng et al. 2020). Since midMarch 2020, the city-state experienced a resurgence of cases due to residents returning from overseas followed by local clusters. The government responded by implementing stricter measures to enforce physical distancing. These 'circuit breaker' measures lasted for 8 weeks (four incubation cycles of SARS-CoV-2) from 7 April 2020 onwards, and included closure of schools and nonessential workplaces in addition to a temporary ban on social gatherings, amounting to a partial lockdown of the city. As of 23 April 2020, there have been 12,075 infected persons and 12 deaths from COVID-19 in Singapore.

The optimal management of breast malignancy entails multidisciplinary cooperation from breast and oncoplastic surgeons, medical and radiation oncologists, palliative services, nursing and allied health professionals. The tremendous adverse impact of the COVID-19 epidemic on the Singapore healthcare system also extends to breast cancer care. This review aims to present the challenges to breast oncology practice in Singapore during this unfurling health crisis. We further set forth recommendations for care continuity planning in the face of resource constraints, which strive to safeguard patients and cancer care professionals against SARS-CoV-2 exposure while upholding therapeutic goals for patients with breast cancer.

\section{Impact of COVID-19 on healthcare system and cancer care services in Singapore}

\section{The healthcare system}

The Singapore medical system predominantly consists of a state-run public sector which administers subsided healthcare to its 5.7-million population, co-existing with a private sector counterpart.

Singapore learnt important lessons from the Severe Acute Respiratory Syndrome (SARS) pandemic in 2003. Since then, systematic efforts to prepare public hospitals for another respiratory disease outbreak included setting up the purpose-built National Centre for Infectious Diseases and National Public Health Laboratory; increasing the number of negative-pressure isolation beds and biosafety level 3 laboratories; stockpiling personal protective equipment (PPE); and training healthcare workers in the correct use of PPE (Wong et al. 2020). The DORSCON system was also developed to guide responses from the whole of government based on the local outbreak status and public health impact during a pandemic (Ministry of Health, Singapore 2014).

Since the infancy of the COVID-19 outbreak, hospital infection prevention and control policies, modified workflows and suspect case definitions have been communicated through daily emails to staff. Clear guidance has been laid for the use of PPE tiered by the type of clinical care setting, while emergency departments and inpatient wards have been re-organised with designated care areas for patients with suspected and confirmed COVID-19. Patient transfers between acute hospitals are minimised and restricted to cases which are clinically indicated. Visitors in public hospitals and outpatient clinics are curtailed and screened for temperature, symptoms and travel history before permitted entry.

Public healthcare workers undergo temperature surveillance twice daily. Staff leave is restricted and overseas travel is prohibited. Staff members who develop fever or respiratory symptoms are seen at designated staff clinics or the emergency department; unwell staff are discouraged from going to work (Lee et al. 2020, Ngoi et al. 2020).

Only essential healthcare services in the public and private sectors remain functional during the 'circuit breaker' period. Supply chains supporting these services also continue to operate.

As the number of local infections rose in April 2020, swab testing for patients meeting criteria became decentralised from public hospitals to include selected primary healthcare clinics.

\section{Cancer care services}

During the 'circuit breaker' period in Singapore, hospitalbased cancer care services, inpatient hospices and home palliative care are considered as essential and remain operational. Otherwise, cancer screening and surveillance services, including the national mammographic screening programme, are categorised as non-essential and have temporarily halted.

As border controls tightened, non-resident referrals and visits to cancer clinics have ceased. Non-urgent clinic 
appointments such as for cancer surveillance are deferred, while telephonic and telemedicine consultations, where appropriate, are used in lieu of face-to-face reviews. Outpatient pharmacies have also switched from on-site dispensation to home delivery of medications.

Cross-institution movement of clinicians is restricted during DORSCON Orange and the 'circuit breaker' period. Tumour boards, radiopathology conferences and other intradepartmental or multidisciplinary meetings are conducted via secure videoconferencing platforms. Furthermore, clinicial teams at cancer centres have split or segregated in inpatient and ambulatory settings on a rotational or full-term basis. One such segregated-team model is described separately (Ngoi et al. 2020).

\section{Recommendations for adaptations to breast oncology practice in Singapore during the COVID-19 pandemic}

\section{Principal considerations and conceptual framework}

The principal considerations in approaching breast cancer care during the COVID-19 pandemic are:

1. Safety: balancing the need to visit cancer care facilities for treatment against patients' risk of exposure to SARS-CoV-2 and between immunosuppression induced by cancer treatment(s) and infection risk

2. Clinical urgency for therapeutic intervention(s)

3. Efficacy of anti-cancer treatment(s): these relate to the desired treatment outcomes and magnitude of treatment benefit

4. Availability of healthcare personnel and resources to safely deliver anti-cancer treatment(s)

5. Quality of life and access to care throughout the patient's care trajectory

It is widely accepted that cancer patients can have weakened immunity secondary to their underlying neoplasm or anti-cancer treatments. In particular, receipt of chemotherapy (within the past three months) or ongoing extensive radiotherapy, leucopaenia, age above 60 years, hospital admission and frequent hospital visits are putative risk factors that predispose cancer patients to SARS-CoV-2 infection (Pentheroudakis et al. 2020, Yu et al. 2020), making mitigating and infection prevention measures for these vulnerable subgroups paramount. Moreover, early reports suggest an association between a history of cancer or its treatments and serious complications from COVID-19 (Liang et al. 2020,
Zhang et al. 2020), with a preliminary case fatality rate of $5.6 \%$ among infected cancer patients in China (Zhou et al. 2020). For the majority of curative and treatment-naive metastatic cases of breast cancers, the probable survival benefit of cancer treatment(s) generally outweighs the risk of death from COVID-19.

Clinical exigency, treatment intent (cure vs palliation of breast cancer), the anticipated extent of therapeutic benefit, disease biology and patient factors influence the prioritisation of cancer treatments during the COVID-19 era. Surgical emergencies (e.g. flap ischaemia, expanding haematoma) and oncological crises (e.g. visceral crisis, cord compression) are examples in breast oncology whereby expeditious interventions are warranted. It is crucial to involve patients closely in a shared decision-making process when the pandemic introduces another layer of complexity, taking into account their preferences for the risks and benefits of accepting vs deferring, interrupting or withholding anti-cancer treatment(s).

During DORSCON Orange and Red levels amidst a worsening COVID-19 outbreak, healthcare personnel and resources are likely to be diverted away from all fields of medicine and surgery, including those involved in breast oncology, to support Singapore's outbreak response efforts. This, along with other systems-level modifications in compliance of infection prevention protocols, will necessitate the rationalisation of limited resources and prioritisation of cancer care for different patient subpopulations.

A conceptual framework has been proposed by other authors for prioritising cancer radiotherapy and systemic treatments during the COVID-19 pandemic (Hanna et al. 2020). We adapted this to articulate our continuity planning strategy for breast cancer care in Singapore, incorporating the DORSCON system (Fig. 1). This construct encapsulates the priority and targeted availability of therapeutic interventions across the phases of the pandemic. We stress that these are guidelines which should not supersede treating oncologists' clinical judgement and patients' choice in personalising treatment plans.

\section{Breast surgery}

Breast surgeons are involved with the diagnosis and treatment of breast cancer. During this COVID-19 pandemic, healthcare resources (e.g. PPE, anaesthetic agents) and surgical manpower will be increasingly limited, and it is vital to avoid exposure of both patients and healthcare professionals to SARS-CoV-2. 


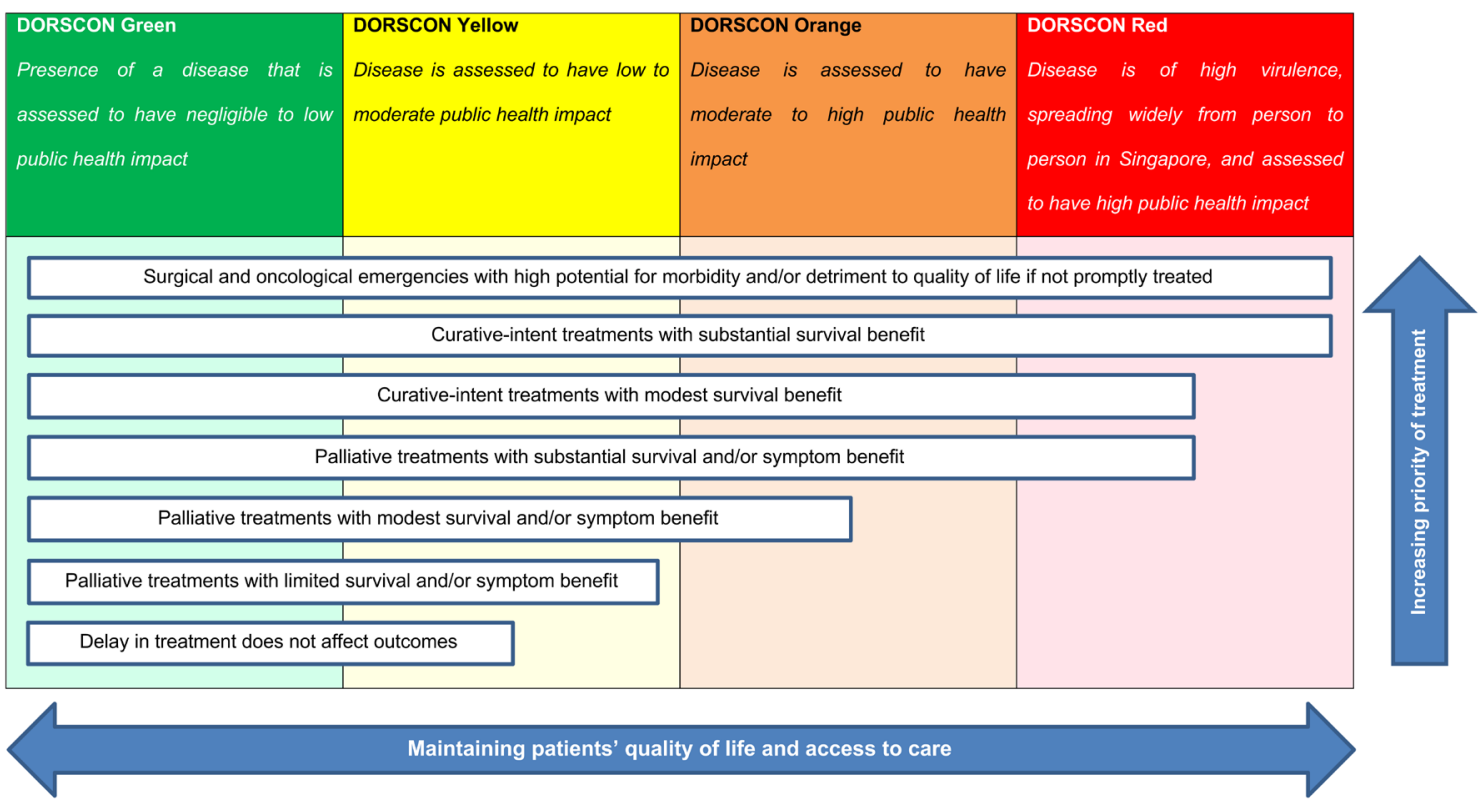

\section{Figure 1}

As the COVID-19 outbreak becomes more widespread in Singapore, the outbreak risk assessment and the whole-of-government, whole-of-society responses have escalated from DORSCON Green through Yellow to Orange. The highest potential alert level is DORSCON Red. A set of intermediary measures referred to as 'circuit breaker' was instituted in April 2020 to prevent the transition from DORSCON Orange to Red (see main text). During DORSCON Orange and Red, less healthcare manpower and resources may be available for the provision of cancer care services because of resource diversion to support the outbreak response and/or logistical constraints to comply with infection control and prevention policies. Within this conceptual framework, the prioritisation of oncological interventions dictates resource commitment to sustain the availability of high-priority, time-sensitive therapies to breast cancer patients through more advanced phases of the outbreak. Across the continuum of DORSCON alert levels, we aim to maintain patients' quality of life and access to care through appropriate treatment selection, innovative models of care delivery (e.g. telemedicine), supportive care measures, and home hospice referral if indicated. Note that the span of the bars (availability of treatments) and the spacing in between them (ranked priority) are for illustrative purposes and not meant to be prescriptive. COVID-19, coronavirus disease 2019; DORSCON, Disease Outbreak Response System Condition.

\section{Diagnosis}

During DORSCON Orange and Red, we recommend concentrating our resources on the diagnosis and staging of breast cancers in symptomatic patients. This is to be achieved with the fewest possible patient visits to hospital.

Criteria for essential referrals are disseminated to primary care colleagues who serve as the first line of triage. Specialist outpatient consultations for new referrals remain available. The aim of the first clinic consultation is to identify patients at high suspicion of having breast cancer. This is aided by the use of bedside ultrasonography. Patients with high pre-test probability for malignancy have diagnostic mammographic and ultrasonographic assessments immediately after the clinic consult. These patients either undergo a biopsy by the surgeon within the same day or are scheduled for imaging-guided biopsy on a separate day. Patients at low suspicion of malignancy are reassured with imaging deferred by an appropriate time interval, ideally after de-escalation of DORSCON status. Staging scans for cancer diagnoses proceed as indicated and are coordinated on a same day if feasible.
This is followed by a single follow-up consultation to discuss the new diagnosis, stage and management plan.

Breast cancer screening in the general population and high-risk patients at hospitals and national screening centres have been suspended until further notice. Nonetheless, assessment clinics for recently screened patients still continue for those with abnormal mammographic findings. Percutaneous biopsies are performed on the day of assessment. Surgery of indeterminate or discordant lesions deemed likely benign have been postponed until DORSCON de-escalation to Green or Yellow.

\section{Treatment}

The principles adhered by the surgical team during this pandemic are to maintain services for breast cancer resection, with considerate use of hospital resources, without compromise to oncological care and outcomes. This entails reducing the potential exposure of patients and healthcare professionals to SARS-CoV-2, as well as the pre-operative identification of COVID-19 infection.
C) 2020 Society for Endocrinology Published by Bioscientifica Ltd. Printed in Great Britain 
At the time of writing, all surgical patients are screened with a questionnaire for travel history, contact and symptoms of COVID-19 before listing for surgery and prior to arrival on the day of operation (Chew et al. 2020). Patients who are screened negative clinically may proceed with their surgery. As we gain new knowledge on asymptomatic transmissions and learn of the increased and significant morbidity and mortality of patients who undergo surgery during the incubation period (Lei et al. 2020), pre-operative screening and testing of all patients for SARS-CoV-2 is under review.

Premised on the hypothesis of droplet and aerosol spread of SARS-CoV-2, we follow guidelines for precautions for operating room team members during the COVID-19 pandemic (Chew et al. 2020). In the rare situation of a breast cancer patient with COVID-19 requiring emergency surgery, the operation shall take place in a designated operating theatre with staff donning N95 masks and fullgear PPE (Ti et al. 2020). In view of rising community spread and number of asymptomatic carriers, all other patients are assumed to be potentially infected with SARSCoV-2 until proven otherwise. To reduce the risk of viral transmission during aerosol-generating intubation and extubation, the anaesthetic team is gowned, gloved and masked (N95 or powered air-purifying respirator) with eye protection (goggles and face shield). All personnel not directly involved in intubation or extubation leave the operating theatre for 10 min before re-entry. This allows for at least two gas exchanges of the operating theatre and enhances safety in case the patient is an undiagnosed COVID-19 case. Surgeons perform breast surgery with standard surgical masks and face shields. Manpower in the operating theatre is kept to a minimum to avoid unnecessary exposure by healthcare workers.

Changes to other aspects of surgical practice have also been introduced to reduce the demands of hospital admissions. Where possible, cases are done as day surgeries. Same-day admission with an overnight stay postoperatively is otherwise recommended for mastectomies, axillary clearances with a surgical drain, and patients with medical comorbidities. Patients who require radiocolloid for sentinel lymph node biopsy undergo a 1-day protocol (instead of 2 days) to reduce hospital visits. For breast conserving surgeries, margin shaves of cavity are performed to reduce re-excision rates (Dupont et al. 2019). On-table ultrasound and specimen ultrasound and/or $\mathrm{X}$-rays are also employed where appropriate (McCormick et al. 2004, Barellini et al. 2019).

Physiotherapists teach post-operative patients shoulder mobilisation before discharge. Videos for rehabilitative exercises and teleconsultation with the therapist for follow-up have been made available.

As part of pandemic planning, we categorise procedures in breast disease-focused surgical oncology by three tiers of priority which are adapted from recommendations of the American Society of Breast Surgeons (Dietz et al. 2020), with tier A being the most urgent and $\mathrm{C}$ the least. Our proposed surgical recommendations according to priority and DORSCON status are shown in Table 1.

During DORSCON Orange and the 'circuit breaker' period, priority $\mathrm{C}$ operations have been deferred, whereas priority B surgeries that are still carried out include the following:

- resection of stage I-III breast cancers, ductal carcinoma in situ (DCIS), tumours post neoadjuvant systemic therapy, locoregional recurrences and Phyllodes tumours (borderline or malignant)

- re-excision of positive margins

- excision of discordant biopsies likely to be malignant

- immediate breast reconstruction

In the event of DORSCON Red and/or should resources become scarcer, the following priority $\mathrm{B}$ surgeries may have to be deferred:

- re-excision surgery

- immediate breast reconstruction: patients will be counselled for placement of a tissue expander, with a delayed definitive reconstruction upon de-escalation of DORSCON to Green or Yellow

- oncological surgeries for less aggressive tumours such as oestrogen receptor (ER) positive DCIS without associated mass (Dietz et al. 2020, Hwang et al. 2020) and cT1-2 N0-1 M0 luminal A-like tumours for which neoadjuvant endocrine therapy (ET) may be considered

- delayed sentinel lymph node biopsy for cancer identified on excisional biopsy

\section{Systemic anti-cancer treatments}

Physical distancing rules implemented from the 'circuit breaker' period onwards mandate a lower patient density at ambulatory chemotherapy units with proportionately fewer appointments available for the i.v. administration of systemic anti-cancer treatments (SACT). Reassignment of medical and nursing personnel to meet pressing demands of COVID-19 also decreases the volume of trained manpower to acutely manage hypersensitivity reactions in chemotherapy units. Broadly, our recommended adaptations for SACT and related supportive care are 
Table 1 Recommendations for breast disease-focused surgical oncology according to priority of care and DORSCON status.

\begin{tabular}{|c|c|c|c|c|c|}
\hline Priority & Description & Clinical situation & $\begin{array}{l}\text { DORSCON Green } \\
\text { and Yellow }\end{array}$ & DORSCON Orange & DORSCON Red \\
\hline \multirow[t]{4}{*}{ A } & $\begin{array}{l}\text { Surgical emergencies } \\
\text { which potentially }\end{array}$ & $\begin{array}{l}\text { Incision and drainage of a breast } \\
\text { abscess }\end{array}$ & $\checkmark$ & $\checkmark$ & $\checkmark$ \\
\hline & threaten the patient's life & Evacuation of haematoma & $\checkmark$ & $\checkmark$ & $\checkmark$ \\
\hline & or reconstructed breast if & Revision of ischaemic mastectomy flap & $\checkmark$ & $\checkmark$ & $\checkmark$ \\
\hline & not expeditiously treated & $\begin{array}{l}\text { Revascularisation/revision of } \\
\text { autologous tissue flap/autologous } \\
\text { reconstruction }\end{array}$ & $\checkmark$ & $\checkmark$ & $\checkmark$ \\
\hline \multirow[t]{12}{*}{ B } & $\begin{array}{l}\text { Cancer treatments which } \\
\text { can be delayed by short } \\
\text { weeks without altering } \\
\text { the clinical course }\end{array}$ & Patients completing NACT & $\checkmark$ & $\checkmark$ & $\begin{array}{l}\checkmark \\
\text { Tumours } \\
\text { progressing on } \\
\text { NACT and } \\
\text { inflammatory BC } \\
\text { take precedence }\end{array}$ \\
\hline & & Resectable TNBC and HER2+ tumours & $\begin{array}{l}\checkmark \\
\text { NACT is recomme }\end{array}$ & ended for high-risk $n$ & Iode positive or LABC \\
\hline & & Resectable HR+ HER2- tumours & $\checkmark$ & $\checkmark$ & $\begin{array}{l}\text { Offer neoadjuvant } \\
\text { ET for cT1-2 N0-1 } \\
\text { luminal A-like } \\
\text { tumours }\end{array}$ \\
\hline & & Re-excision of positive margins & $\checkmark$ & $\checkmark$ & $\begin{array}{l}\text { Defer until } \\
\text { de-escalation of } \\
\text { DORSCON }\end{array}$ \\
\hline & & Resection of DCIS & $\checkmark$ & $\checkmark$ & $\checkmark$ \\
\hline & & $\begin{array}{l}\text { - } \text { ER+ DCIS with an associated mass } \\
\text { - } E R-\text { DCIS }\end{array}$ & & & \\
\hline & & $\begin{array}{l}\text { Resection of ER+ DCIS without an } \\
\text { associated mass }\end{array}$ & $\checkmark$ & $\checkmark$ & $\begin{array}{l}\text { Defer if surgical } \\
\text { resources do not } \\
\text { allow. Consider } \\
\text { neoadjuvant ET. }\end{array}$ \\
\hline & & $\begin{array}{l}\text { Immediate breast reconstruction } \\
\text { (autologous microsurgery free-flaps) }\end{array}$ & $\checkmark$ & $\checkmark$ & $\begin{array}{l}\text { Defer. Counsel } \\
\text { patients for tissue } \\
\text { expander with } \\
\text { delayed definitive } \\
\text { reconstruction. }\end{array}$ \\
\hline & & $\begin{array}{l}\text { Wide excision of borderline or } \\
\text { malignant Phyllodes tumours }\end{array}$ & $\checkmark$ & $\checkmark$ & $\checkmark$ \\
\hline & & $\begin{array}{l}\text { Discordant biopsies likely to be } \\
\text { malignant }\end{array}$ & $\checkmark$ & $\checkmark$ & $\checkmark$ \\
\hline & & Excision of malignant recurrence & $\checkmark$ & $\checkmark$ & $\checkmark$ \\
\hline & & $\begin{array}{l}\text { Delayed sentinel lymph node biopsy } \\
\text { for cancer identified on excisional } \\
\text { biopsy }\end{array}$ & $\checkmark$ & $\checkmark$ & $\begin{array}{l}\text { Defer until } \\
\text { de-escalation of } \\
\text { DORSCON }\end{array}$ \\
\hline \multirow[t]{7}{*}{ C } & \multirow{7}{*}{$\begin{array}{l}\text { Non-urgent surgeries } \\
\text { which can be deferred for } \\
\text { the entire duration of the } \\
\text { outbreak }\end{array}$} & $\begin{array}{l}\text { Excision of benign lesions, for } \\
\text { example, fibroadenomas, nodules }\end{array}$ & $\checkmark$ & \multicolumn{2}{|c|}{ Defer until de-escalation of DORSCON } \\
\hline & & Microdochectomy & $\checkmark$ & \multicolumn{2}{|c|}{ Defer until de-escalation of DORSCON } \\
\hline & & Discordant biopsies likely to be benign & $\checkmark$ & \multicolumn{2}{|c|}{ Defer until de-escalation of DORSCON } \\
\hline & & $\begin{array}{l}\text { High-risk lesions, for example, atypia, } \\
\text { papillomas }\end{array}$ & $\checkmark$ & \multicolumn{2}{|c|}{ Defer until de-escalation of DORSCON } \\
\hline & & $\begin{array}{l}\text { Excision of screen-detected } \\
\text { indeterminate lesions }\end{array}$ & $\checkmark$ & \multicolumn{2}{|c|}{ Defer until de-escalation of DORSCON } \\
\hline & & $\begin{array}{l}\text { Prophylactic surgery for cancer and } \\
\text { non-cancer }\end{array}$ & $\checkmark$ & \multicolumn{2}{|c|}{ Defer until de-escalation of DORSCON } \\
\hline & & Palliative toilet mastectomy & $\checkmark$ & \multicolumn{2}{|c|}{$\begin{array}{l}\text { Defer until de-escalation of DORSCON. } \\
\text { Continue palliative SACT and nursing } \\
\text { care. Consider palliative RT. }\end{array}$} \\
\hline
\end{tabular}

$\checkmark$, can proceed with the operation depending on institutional resource availability.

BC, breast cancer; DCIS, ductal carcinoma in situ; DORSCON, Disease Outbreak Response System Condition; ER, oestrogen receptor; ET, endocrine therapy; HER2, human EGF receptor 2; NACT, neoadjuvant chemotherapy; RT, radiotherapy; SACT, systemic anticancer treatments; TNBC, triple negative breast cancer.

https://erc bioscientifica com https://doi.org/10.1530/ERC-20-0157 (c) 2020 Society for Endocrinology Published by Bioscientifica Ltd. Printed in Great Britain 
designed to conserve resources which will be constrained by the pandemic while preserving standards of care as much as possible by minimising:

- the frequency of patient visits to outpatient units and unscheduled hospital admissions for the management of treatment-related adverse events

- the incidence of hypersensitivity reactions and febrile neutropaenia

- the utilisation of emergency, diagnostic and supportive services

During DORSCON Orange and Red in Singapore, we advocate the following strategies:

- Involve patients in shared decision-making, factoring in their acceptance for the commencement or continuation of SACT during the pandemic

- Consider alternative regimens, dose schedules (three/ four weekly instead of one/two weekly) or formulations (oral or s.c. as opposed to i.v.) which are of equivalent or non-inferior efficacy to the conventional standard of care (i.e. no compromise to survival outcomes)

- Consider alternative agents for drugs that are prone to hypersensitivity reactions, for example, paclitaxel and carboplatin

- Consider primary prophylactic granulocyte colonystimulating factor (GCSF) for regimens associated with moderate to high risk for febrile neutropaenia

- Avoid elective admissions for diagnostic procedures and drug desensitisation unless absolutely necessary because of limited hospital beds

- Employ telemedicine options wherever possible

- Manage patients' expectations after modifications to cancer care delivery. Educate and empower patients to monitor and self-manage low-grade toxicities, for example, providing 'care packs' of symptomatic medicines and telephone helplines operated by specialist nurses to render supportive care advice

\section{(i) Curative-intent treatments}

The rationale for our recommendations in terms of (neo) adjuvant SACT (Table 2) is presented according to breast cancer subtypes subsequently. Additional guidelines for adjunctive supportive care are included in Table 2.

\section{Triple negative breast cancer}

Triple negative breast cancers (TNBC) generally have a more aggressive biology than other subtypes of breast cancer.
Neoadjuvant chemotherapy We recommend neoadjuvant chemotherapy (NACT) in the majority of tumours which are clinically $2 \mathrm{~cm}$ or greater in diameter (T2-4) or node positive, with the aim of downsizing and potentially improving the chance of breast conservation, as well as prognostication in the event of pathologic complete response (pCR) (Cortazar et al. 2014). The regimens of choice include sequential anthracycline and taxane (with or without platinum) for higher risk disease (Cardoso et al. 2019), as well as de-escalated anthracycline-sparing regimens like docetaxel and cyclophosphamide for lower risk disease (Jones et al. 2009). In cases of low clinical risk (cT1N0) or if the patient is considered at high inherent risk of chemotherapy-related toxicities, advocating primary oncological resection may optimise overall patient outcome and healthcare resource utilisation.

Adjuvant chemotherapy Post-NACT, patients who did not attain pCR should be offered adjuvant capecitabine based on survival benefit seen in the CREATE- $X$ trial (Masuda et al. 2017). Patients who underwent primary breast surgery and have tumours greater than $0.5 \mathrm{~cm}$ in diameter should be offered adjuvant chemotherapy starting up to 6 weeks post-surgery (Cardoso et al. 2019), with shorter regimens preferred at DORSCON Orange/Red.

\section{HER2+ breast cancer}

In addition to chemotherapy principles highlighted previously, the addition of anti-human EGF receptor 2 (HER2) therapy has consistently shown to improve both disease-free survival (DFS) and overall survival (OS) in an adjuvant setting. In the neoadjuvant setting, addition of anti-HER2 therapy is also preferred in view of improved pCR rates that has both prognostic and therapeutic implications based on best evidence today. As such, anti-HER2 therapy should continue to be administered together with (neo)adjuvant chemotherapy wherever possible. Subcutaneous trastuzumab is favoured over the i.v. formulation to save chemotherapy chair time and decrease risk of exposure for both patients and healthcare workers (Jackisch et al. 2015, Gligorov et al. 2017).

Neoadjuvant SACT NACT in combination with antiHER2 therapy is an excellent therapeutic option with high pCR rates (Cortazar et al. 2014) and should be considered if surgical resources are limited in the background of COVID-19. Patients with tumours which regressed 
Table 2 Recommendations for SACT and supportive care of early breast cancer according to DORSCON status.

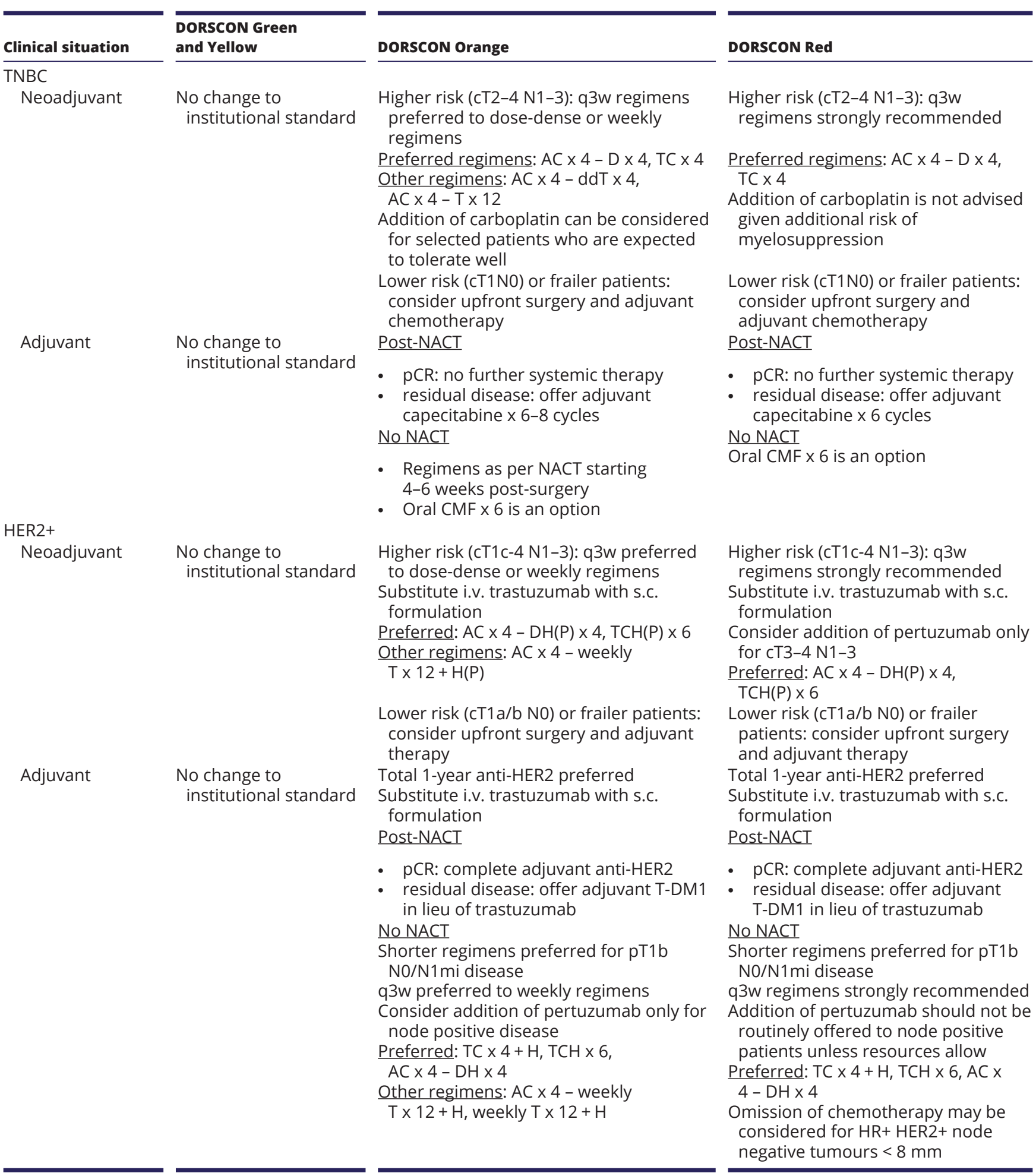


Table 2 Continued.

\section{Clinical situation}

HR+ HER2-

Neoadjuvant

\section{DORSCON Green and Yellow}

No change to institutional standard

\section{DORSCON Orange}

Higher risk (cT2-4 N1-3):

If upfront operable, consider surgery

If surgery is not feasible, NACT

recommended if downsizing will improve surgical outcomes

q3w preferred to dose-dense or weekly regimens

Preferred: AC x 4 - D $\times 4, T C \times 4$

Other regimens: AC x 4 - ddT $\times 4, A C \times 4$ - Tx 12

Lower risk (cT1-2 N0-1) or frailer patients: Upfront surgery and adjuvant therapy

Post-menopausal patients with luminal A-like tumoursa: consider trial of neoadjuvant ET

\section{Adjuvant}

\section{No change to} institutional standard

Supportive care
Fertility
preservation

Primary
prophylactic
GCSF
Cardiac function
monitoring for
anti-HER2/
nthracycline
OFS
Bone-modifying
agents

No change to institutional standard Oocyte harvesting or ovarian tissue cryopreservation is available

No change to institutional standard

\section{No change to} institutional standard

No change to institutional standard

No change to institutional standard paclitaxel, TCH(P)
Consider q3m GnRH agonist for the short term

Choose oral anti-resorptive agent if treating osteoporosis

\section{Post-NACT: ET}

No NACT

Decision for adjuvant chemotherapy

based on clinicopathologic factors and/or precision testing

High risk of recurrence: can offer chemotherapy (q3w preferred to dose dense or weekly regimens) starting 4-6 weeks post-surgery, followed by ET Intermediate risk of recurrence: consider q3m OFS and tamoxifen or Al in lieu of chemotherapy in pre-menopausal women. ET alone in post-menopausal women.

Low risk of recurrence: ET alone

Option limited to OFS with GnRH agonist

Option limited to OFS with GnRH agonist (use q3m formulation)

Post-NACT: ET

No NACT

Decision for adjuvant chemotherapy based on clinicopathologic factors and/or precision testing (if available)

High risk of recurrence: can offer q3w chemotherapy starting 6 weeks post-surgery, followed by ET Intermediate risk of recurrence: consider q3m OFS and tamoxifen or $\mathrm{Al}$ in lieu of chemotherapy in pre-menopausal women. ET alone in post-menopausal women.

Low risk of recurrence: ET alone
Higher risk (cT2-4 N1-3):

If upfront operable, consider surgery If surgery is not feasible, offer NACT

with $\mathrm{q} 3 \mathrm{w}$ regimens

Preferred: AC x 4 - D x 4, TC x 4

Lower risk (cT1-2 N0-1) or frailer patients:

Upfront surgery and adjuvant therapy Post-menopausal patients with luminal A-like tumoursa: offer trial of neoadjuvant ET

Pre-menopausal patients with luminal A-like tumoursa: offer trial of neoadjuvant ET + OFS

Routine use for regimens, for example, AC, TC, docetaxel-based, dose dense

Delay monitoring or increase interval from q3m to $q 4-5 m$ as long as patient is asymptomatic for LVEF dysfunction and prior LVEF $\geq 50 \%$

Use q3m GnRH agonist for the short term Avoid initiating new therapy Suspend ongoing i.v. therapy

alow grade, strongly ER+, PR+, HER2-, low proliferative fraction.

AC, doxorubicin, cyclophosphamide; Al, aromatase inhibitor; CMF, cyclophosphamide, methotrexate, fluorouracil; ddT, dose dense (2-weekly) paclitaxel; $\mathrm{DH}(\mathrm{P})$, docetaxel, trastuzumab, pertuzumab; DORSCON, Disease Outbreak Response System Condition; ER, oestrogen receptor; ET, endocrine therapy; GCSF, granulocyte colony-stimulating factor; GnRH, gonadotrophin releasing hormone; HER2, human EGF receptor 2; $H(P)$, trastuzumab, (pertuzumab); HR, hormone receptor; LVEF, left ventricular ejection fraction; NACT, neoadjuvant chemotherapy; N1 mi, microinvasive disease in lymph nodes; OFS, ovarian function suppression; $p C R$, pathological complete response; PR, progesterone receptor; q3m, once 3-monthly; q3w, once 3-weekly; q4-5m, once in 4-5 months; SACT, systemic anti-cancer therapy; TC, docetaxel, cyclophosphamide; TC + H, docetaxel, cyclophosphamide + trastuzumab; TCH(P), docetaxel, carboplatin, trastuzumab, (pertuzumab); T-DM1, trastuzumab emtansine; TNBC, triple negative breast cancer; weekly T, weekly paclitaxel. 
inadequately (i.e. non-pCR) after pre-operative antiHER2-based SACT can consider risk-adapted adjuvant strategies that may improve disease-free survival, further elaborated in the next section. As such, neoadjuvant SACT should be strongly considered in patients with tumours larger than $1 \mathrm{~cm}(\geq \mathrm{T} 1 \mathrm{c})$ or node positive disease (Gianni et al. 2014).

Compared with single-agent HER2 blockade, dual anti-HER2 therapy further increases the likelihood of achieving pCR (Schneeweiss et al. 2013, Gianni et al. 2016). Therefore, NACT plus dual anti-HER2 therapy can be considered, especially for patients with locally advanced HER2+ disease. In patients with good performance status, consideration of docetaxel, carboplatin, trastuzumab and pertuzumab (TCHP) for six cycles may potentially reduce total treatment duration and represents an anthracycline-sparing option to reduce the risk of cardiotoxicity (Schneeweiss et al. 2013). Should sequential anthracycline- and taxane-containing regimens be chosen as the chemotherapy backbone, use of docetaxel instead of paclitaxel can be considered to obviate the need for weekly infusions of the latter.

Adjuvant SACT We advocate the completion of a year's HER2 blockade wherever possible, due to robust evidence of improved treatment outcomes compared to no therapy. Nonetheless, in selected patients for whom cardiotoxicity is of concern or who have multiple comorbidities putting them at high risk of developing COVID-19, the option of HER2 blockade for total 6 months may be discussed after weighing the risk-benefit ratio (Earl et al. 2019). Truncating adjuvant anti-HER2 therapy may be considered in DORSCON Red, particularly if the risk of COVID-19 infection and resource limitation outweigh the benefits of completing a full year of treatment.

Following neoadjuvant SACT, the choice of adjuvant anti-HER2 therapy is largely guided by neoadjuvant response. Among patients with residual invasive disease, adjuvant trastuzumab emtansine (T-DM1) has been shown to improve invasive DFS over trastuzumab and can be considered (von Minckwitz et al. 2019).

For patients who underwent upfront surgery, adjuvant anti-HER2 therapy should be administered together with chemotherapy. In patients with node positive disease, the guiding principles for chemotherapy choice are consistent with those stated in the neoadjuvant setting. Adjuvant dual HER2 blockade has demonstrated benefit especially for higher stage disease and may be discussed with patients with node positive disease (von Minckwitz et al. 2017), although the resource availability to administer

(c) 2020 Society for Endocrinology Published by Bioscientifica Ltd. Printed in Great Britain pertuzumab may be limited under dire DORSCON Red conditions.

In patients with node negative or microscopic disease (pNO/N1mi) and small primary tumours (pT1b-2), we recommend 3-weekly docetaxel/cyclophosphamide with trastuzumab over weekly paclitaxel-trastuzumab to reduce outpatient visits (Jones et al. 2013). Adjuvant T-DM1 may be an alternative for stage I patients (Dietz et al. 2020) who may be at higher risk of developing chemotherapy toxicities or decline doublet/weekly chemotherapy, based on unpublished data from the phase II ATEMPT trial (ClinicalTrials.gov identifier NCT01853748). In an extreme DORSCON Red setting, omission of adjuvant multiagent chemotherapy may be considered for hormone receptor (HR) positive, HER2+ node negative tumours smaller than $8 \mathrm{~mm}$ on the basis of an observational cohort study suggesting that chemotherapy does not confer incremental OS benefit over ET for such cases (Cardoso et al. 2019, Ma et al. 2020).

\section{HR+ HER2- breast cancer}

Hormone receptor (HR) positive, HER2 negative breast cancers are heterogeneous, with luminal A tumours being more indolent and strongly endocrine sensitive whereas luminal B tumours being more aggressive (Cardoso et al. 2019).

Neoadjuvant and adjuvant chemotherapy The role of NACT in HR+ HER2- breast cancer is limited because pCR rates are lower compared to TNBC or HER2+ tumours and correlate weakly with long-term survival outcomes (Cortazar et al. 2014). NACT is typically indicated in HR+ HER2- primary breast cancers which are locally advanced or upfront inoperable. Primary surgery particularly for early stage breast cancer (cT1-2 N0-1) allows for precision testing, for example, Oncotype DX to inform post-operative treatments; the necessity for adjuvant chemotherapy and sequelae from immunosuppression may be eliminated in patients with good prognostic indices (Sparano et al. 2018). After primary surgery, if patients are determined to have high risk disease based on precision testing and/or clinicopathologic factors, adjuvant chemotherapy using the previously mentioned principles should be offered.

Neoadjuvant and adjuvant endocrine therapy Many patients with early stage HR+ HER2- breast cancer need not undergo chemotherapy, particularly in the modern era of precision testing. In a subset of patients with luminal A-like breast cancers (low grade, strongly ER+, 
strongly progesterone receptor positive, HER2- and low proliferative fraction) who are otherwise well, neoadjuvant ET can serve as a bridge to reduce the need for surgery and chemotherapy for 6 to 8 months (Smith et al. 2005, Masuda et al. 2012), which will be a resourcefriendly strategy in DORSCON Red. Pre-menopausal patients, particularly those with intermediate risk scores on Oncotype DX, can also consider the option of ovarian function suppression (OFS) in conjunction with ET in lieu of adjuvant chemotherapy (Francis et al. 2018). Follow-up consultations while on ET can be stretched up to 3- to 6-monthly intervals which are desirable in higher DORSCON alert levels.

\section{(ii) Palliative treatments}

The following are guiding principles in caring for patients with inoperable or metastatic breast cancer during the COVID-19 pandemic:

- Delay therapy when the expected efficacy is modest, maintenance therapies, and treatments for patients with low disease burden and slow progression. Consider treatment breaks if appropriate

- Delay non-urgent radiological scans including for response assessment

- Increase the duration of a treatment cycle, for example, from 3-weekly to 4-weekly, or choose alternative dose schedules, for example, biweekly eribulin

- When initiating a new SACT, an alternative oral agent or non-i.v. route of administration of the same drug is preferred to i.v. if their anticipated efficacy is similar

- Consider non-i.v. maintenance therapy, if appropriate, after sustained partial response or stable disease

- Refer patients on best supportive care (BSC) to home hospice service if appropriate

Our recommendations for palliative treatments are summarised in Table 3 and elaborated subsequently.

\section{Triple negative breast cancer}

In the setting of DORSCON Green/Yellow, we will still primarily consider TNBC patients for trial enrolment while clinical trials remain for recruitment. Several ongoing trials at academic cancer centres in Singapore are in late phases and evaluate combinations of chemotherapy, immunotherapy and/or targeted therapies.

Cytotoxics remain the mainstay of standard SACT for TNBC. Taxanes, platinum salts, anthracyclines, eribulin and capecitabine as single agents or as combination for heavy tumour burden are options for TNBC patients (Cortés et al. 2011, Tutt et al. 2018), with consideration for competing comorbidities and toxicities. Poly(ADPribose) polymerase inhibitors may be considered for the treatment of germline $B R C A$ mutated breast cancers as well as preferentially over chemotherapy in treatmentnaive patients due to their convenient oral administration and lower myelosuppression (Robson et al. 2017).

The combination of atezolizumab and nab-paclitaxel as first-line therapy in TNBC (Schmid et al. 2018) is not approved or routinely accessible in Singapore. We note that immune checkpoint inhibition may elicit pneumological toxicities with features overlapping COVID-19 related interstitial pneumonia. Furthermore, a theoretical synergism between COVID-19 pathogenesis and immunotherapy may both promote immune hyperactivation (Mehta et al. 2020).

During DORSCON Orange/Red, trial recruitment shall halt. In patients with low tumour or symptom burden or declining i.v. chemotherapy, or if i.v. SACT resources are restricted during DORSCON Red, oral chemotherapy such as capecitabine is recommended. Otherwise, 3-weekly docetaxel or carboplatin are reasonable first-line i.v. agents (Tutt et al. 2018) and can be crossed over to the other drug in the second line upon disease progression. In patients who have had maximal response to i.v. chemotherapy, we consider switch to oral maintenance with capecitabine or metronomic cyclophosphamide/methotrexate (Fedele et al. 2012, Munzone \& Colleoni 2015). In selected patients with low-volume, well-controlled disease, it is appropriate to offer a short chemotherapy holiday. Finally, we consider BSC after progression on third-line therapy where the anticipated therapeutic benefits are modest at best.

\section{HER2+ breast cancer}

In the first line during DORSCON Orange/Red, docetaxel once 3-weekly with primary prophylactic GCSF is preferred to weekly paclitaxel, as the chemotherapy partner to HER-directed therapies (Swain et al. 2020). T-DM1 is an acceptable alternative to frontline taxane plus trastuzumab because the former is non-inferior for efficacy and better tolerated (Perez et al. 2017). In patients with HR+ HER2+ tumours and low disease burden, especially those who decline i.v. therapy, first-line ET plus HER2 blockade is reasonable (Kaufman et al. 2009, Huober et al. 2012). T-DM1 or oral capecitabine/lapatinib are our recommended regimens in the second or third line (c) 2020 Society for Endocrinology Published by Bioscientifica Ltd. Printed in Great Britain 
(Diéras et al. 2017, Krop et al. 2017). For HR+ HER2+ patients who have benefitted from induction i.v. chemotherapy, an early switch to maintenance ET plus anti-HER2 therapy can be considered (Cardoso et al. 2018).

Treatment benefit beyond the second or third line may be modest for some patients with HER2+ MBC; non-i.v. chemotherapy-based or chemotherapy-sparing regimens are suggested if initiated for this indication. During the COVID-19 pandemic, it is possible to increase the dosing interval of maintenance trastuzumab from 3-weekly to 4 -weekly to reduce visits. We also recommend suspending or discontinuing maintenance trastuzumab for patients on extended therapy longer than 2 years (Dietz et al. 2020). Wherever possible, i.v. trastuzumab should be substituted with the s.c. formulation (Pivot et al. 2017) to reduce the length of time spent for drug administration.

\section{HR+ HER2 - breast cancer}

Among patients with de novo metastatic HR+ HER2- breast cancer or who relapsed more than 12 months after adjuvant ET, those with bone-limited disease can receive first-line non-steroidal aromatase inhibitor (NSAI) monotherapy; NSAI plus cyclin dependent kinase 4/6 (CDK4/6) inhibitor is recommended for those with moderate to high visceral disease (not in crisis) or symptom burden (Spring et al. 2020). Otherwise, during DORSCON Orange/Red, it is possible to commence the aromatase inhibitor (AI) first for patients with low-volume visceral metastases and add the CDK4/6 inhibitor later when the COVID-19 pandemic eases. Our recommended first-line therapy for patients with early relapse during or within 12 months of adjuvant ET is fulvestrant, preferably with CDK4/6 inhibitor (Spring et al. 2020). The same guidance for a phased introduction of the CDK4/6 inhibitor where suitable as mentioned previously applies. Clinicians should consider toxicity profiles and monitoring parameters when choosing a CDK4/6 inhibitor during the pandemic.

First-line patients on a stable dose of CDK4/6 inhibitor therapy can be reviewed 2-monthly instead of monthly or considered for a treatment break with continuation of AI alone, when DORSCON is Orange/Red.

For the initiation of second-line therapy, we recommend single-agent ET. ET combinations with everolimus or alpelisib have not shown OS benefit (Piccart et al. 2014, André et al. 2019). A potential improvement in progression-free survival must be weighed against toxicities associated with these agents, for instance non-infective pneumonitis which is relevant during a respiratory infection outbreak.
Premenopausal women receiving AI or fulvestrant in any line should receive concurrent OFS.

We recommend oral capecitabine as the first cytotoxic chemotherapy to initiate for endocrine resistant patients after progression on prior endocrine-based therapies and not requiring rapid response.

\section{(iii) Supportive care}

During DORSCON Orange/Red, we recommend against initiating bone-modifying agents in the curative or palliative settings unless treating severe hypercalcaemia. Subcutaneous denosumab can be considered as a substitute for i.v. bisphosphonate as adjunctive treatment of bone metastases. Dosing intervals for ongoing supportive care interventions can also be increased, for instance zoledronate (van Poznak et al. 2017) or gonadotropin-releasing hormone analogue for OFS from monthly to 3-monthly. Likewise, elective on-treatment cardiac function monitoring can be delayed during DORSCON Orange/Red as long as patients do not exhibit cardiac symptoms and have preserved ejection fractions on previous measurements.

\section{(iv) Clinical trials}

COVID-19 impacts the conduct of clinical trials. Considerations include travel restrictions both internationally and locally, quarantine of patients, site closure, interruptions to supply chain of investigational products, reassignment of study staff to COVID-19 related work, challenges in on-site monitoring visits and infection risk of site personnel and trial subjects. The Health Sciences Authority of Singapore issued guidance on trial conduct during the outbreak to aid sponsors and investigators in ensuring the safety of trial subjects while complying with trial regulations and Good Clinical Practice, thereby minimising risk to trial integrity. During DORSCON Yellow, clinical trials within academic medical centres are reviewed and classified as (1) essential studies providing what is considered equivalent to standard of care; (2) intermediate priority such as studies fulfilling unmet clinical needs; or (3) low priority studies. The categorisation criteria are:

- The investigational product, safety, efficacy and extent of clinical experience

- The ability to manage adverse events and to implement dose modifications or delays as necessary in a timely fashion 
Table 3 Recommendations for SACT and supportive care of inoperable and metastatic breast cancer according to DORSCON status.

\begin{tabular}{ll}
\hline Clinical situation & $\begin{array}{l}\text { DORSCON Green } \\
\text { and Yellow }\end{array}$ \\
\cline { 1 - 1 } & $\begin{array}{l}\text { No change to } \\
\text { institutional } \\
\text { standard }\end{array}$
\end{tabular}

DORSCON Orange

$1 \mathrm{~L}$ : clinical triala ${ }^{\mathrm{a}}$ docetaxelb or carboplatin

Consider combination chemotherapy only for high tumour

burden whereby rapid response is desired

2L: clinical triala, switch from docetaxel to carboplatin or vice versa, capecitabine, eribulin ${ }^{b}$

\section{DORSCON Red}

1L: docetaxelb or carboplatin. Capecitabine is recommended if i.v. SACT resources are limited.

Avoid combination chemotherapy unless absolutely indicated (e.g. visceral crisis)

2L: capecitabine, oral vinorelbine, switch from docetaxel to carboplatin or vice versa, eribulin ${ }^{\mathrm{b}}$

Consider PARP inhibitor for known germline BRCA mutation carriers, especially in earlier lines

Consider switch to oral maintenance (capecitabine or metronomic cyclophosphamide/ methotrexate) upon maximal response

Consider short chemotherapy breaks

Consider increasing chemotherapy cycles from 3-weekly to 4-weekly or alternative dose schedules

Consider BSC after progression on $3 \mathrm{~L}$ therapy where anticipated therapeutic benefits are modest
HER2+
institutional standard

1L: $\mathrm{DH}(\mathrm{P})^{\mathrm{b}}$ preferred to $\mathrm{TH}(\mathrm{P})$; ET + anti-HER2 is possible for selected HR+ patients

2L-3L: T-DM1 or capecitabine/lapatinib

1L: DH(P)b or T-DM1; consider ET + anti-HER2 for $\mathrm{HR}+$ patients with low-volume disease 2L-3L: capecitabine/ lapatinib preferred to T-DM1

$\mathrm{HR}+$ : switch to maintenance ET + anti-HER2 if possible Increase dosing interval of maintenance trastuzumab (q4w) Suspend or discontinue maintenance trastuzumab for patients on extended therapy (> 2 years)

Substitute i.v. trastuzumab with s.c. formulation

Therapy beyond 2L-3L: consider capecitabine/lapatinib, capecitabine/trastuzumab, lapatinib/trastuzumab

Delay cardiac function monitoring (if done) as long as patient is asymptomatic and prior LVEF $\geq 50 \%$

HR+ HER2- $\quad$ No change to institutional standard

$1 \mathrm{~L}$ : NSAI (bone-limited, de novo MBC or late relapsec); NSAI \pm CDK4/6i (visceral metastases or symptomatic, de novo MBC or late relapsec); fulvestrant \pm CDK4/6i (early relapse ${ }^{d}$ )

2L: ET monotherapy (fulvestrant, alternative Al, tamoxifen)

Stable CDK4/6i dose: convert to $\mathrm{q} 2 \mathrm{~m}$ reviews or consider break (continue ET alone) OFS for pre-menopausal patients: convert GnRH agonist to q3m formulation Endocrine-resistant patients: capecitabine is the preferred first cytotoxic chemotherapy $-$

Suspend therapy, especially if patient is on oral SACT only

institutional standard
Avoid initiating new therapy (unless treating severe hypercalcaemia)

Consider s.c. denosumab instead of i.v. bisphosphonate Increase dosing intervals, for example, i.v. zoledronate q3m

aapplicable to patients already enrolled in clinical trials. Trial screening and recruitment shall be suspended during DORSCON Orange/Red; bwith primary prophylactic GCSF; cLate relapse refers to cancer recurrence greater than 12 months after adjuvant ET; dEarly relapse refers to cancer recurrence during or within 12 months of adjuvant ET.

1L, first line; 2L, second line; 3L, third line; Al, aromatase inhibitor; BSC, best supportive care; CDK4/6i, cyclin D kinase 4/6 inhibitor; DH(P), docetaxel, trastuzumab and pertuzumab; DORSCON, Disease Outbreak Response System Condition; ET, endocrine therapy; GCSF, granulocyte colony-stimulating factor; GnRH, gonadotrophin releasing hormone; HER2, human EGF receptor 2; HR, hormone receptor; LVEF, left ventricular ejection fraction; NSAI, non-steroidal aromatase inhibitor; OFS, ovarian function suppression; PARP, poly(ADP-ribose) polymerase; q2m, once 2-monthly; q3m, once 3-monthly; q4w, once 4-weekly; SACT, systemic anti-cancer therapy; T-DM1, trastuzumab emtansine; TH(P), paclitaxel, trastuzumab and pertuzumab; TNBC, triple negative breast cancer. 
- The disease under study

- The ability to comply with study related procedures and alternative methods for safety monitoring of trial participants without impacting data credibility

Trials considered essential or of intermediate priority may continue without amendment, but low-priority trials are temporarily halted. During DORSCON Orange/Red, to support national efforts in COVID-19 containment and to conserve hospital resources, trial screening and recruitment shall be suspended. Where permissible on protocol, i.v. study drug administration and studyrelated visits are delayed. Investigators exercise clinical discretion in ensuring that essential safety assessments are completed. Where feasible, remote study visits are considered and oral investigational products are delivered to trial participants.

\section{Radiotherapy}

Prioritisation of radiotherapy (RT) is based on treatment indication as per the conceptual framework in Fig. 1. The highest priority is accorded to treatments for function-threatening cases (e.g. acute cord compression with paralysis, proptosis from retroorbital metastases, intractable tumoral bleeding), followed by treatments associated with OS benefit, then those with locoregional DFS benefit only and, lastly, other palliative treatments. We highlight situations in which RT can be reasonably abbreviated or omitted during this pandemic. Our recommendations in Table 4 are tiered and situational; for instance, use of the most hypofractionated regimen for invasive breast cancer and omission of RT for DCIS during DORSCON Red.

\section{(i) Adjuvant RT}

\section{DCIS}

In low-risk cases (i.e. age 50 years or older with no necrosis, low grade, small tumour size, at least $2 \mathrm{~mm}$ margins), omission of RT is to be strongly considered. The UK/ANZ trial showed that adjuvant RT reduced ipsilateral breast tumour recurrence (IBTR) rate but with no survival benefit (Cuzick et al. 2011). For higher-risk cases, treatment should be abbreviated to use large doseper-fraction hypofractionation regimen.

DCIS comprised about 25\% of the NSABP-B39 trial cohort. This study demonstrated no statistically significant difference in 10-year cumulative incidence of IBTR between whole breast irradiation (WBI) and accelerated partial breast irradiation (APBI). Despite NSABP-B39 not fulfilling equivalence criteria of APBI (38.5 Grays (Gy) in ten fractions delivered twice a day over 5-8 days) to WBI, there was only a marginal $1 \%$ absolute difference in 10-year cumulative incidence of IBTR (Vicini et al. 2019). In contrast, RAPID trial demonstrated that APBI delivered in similar fashion was non-inferior to WBI in preventing IBTR (Whelan et al. 2019) due to its stricter eligibility criteria. Nonetheless, during an active pandemic, oncedaily treatment is preferred for ease of logistics and safe distancing considerations. Therefore, the RT regimen using $40 \mathrm{~Gy}$ in ten daily fractions is preferred (Braunstein et al. 2019). Should WBI be indicated, we recommend the shorter fractionation of FAST FORWARD regimen (26 Gy in five daily fractions) as a pragmatic solution (FAST Trialists Group 2011). During DORSCON Red, we recommend omission of RT for DCIS cases.

\section{Invasive breast cancers}

Node negative breast cancer Before surgery, patients with clinically node negative disease should be screened for eligibility for intraoperative radiotherapy according to TARGIT trial (Vaidya et al. 2014). Post-operatively, patients aged 65 years and above with HR+ tumours shall be considered for potential omission of RT which only modestly reduces IBTR compared to ET alone (Kunkler et al. 2015).

For low-risk patients aged 40-64 years (maximum tumour size $3 \mathrm{~cm}, \mathrm{ER}+$ and receiving adequate systemic treatment), APBI, partial breast irradiation (Coles et al. 2017) and WBI are applicable. Livi et al. showed no significant differences in IBTR or OS between APBI and WBI. Additionally, patients in the APBI arm experienced better cosmetic outcomes and fewer toxicities. Therefore, $30 \mathrm{~Gy}$ in five fractions daily using intensity-modulated radiotherapy technique (Livi et al. 2015) or $40 \mathrm{~Gy}$ in ten fractions daily using 3D conformal RT (Braunstein et al. 2019) may be employed, if the APBI method is selected. Where WBI is indicated, standard hypofractionation regimen of 40 Gy in 15 fractions (Haviland et al. 2013) shall be used. The FAST FORWARD regimen is an alternative (FAST Trialists Group 2011). During DORSCON Red, options are restricted to APBI using 30 Gy in five fractions or WBI using 26 Gy in five fractions.

In all other patients (age 40 years or younger; or highrisk, age above 40 years; or tumours larger than $3 \mathrm{~cm}$, of high grade, ER-, HER2+ or involved margin), WBI (or postmastectomy RT [PMRT] for tumours larger than $5 \mathrm{~cm}$ or c) 2020 Society for Endocrinology Published by Bioscientifica Ltd. Printed in Great Britain 
positive margin) with either standard hypofractionation 40 Gy in 15 fractions or the FAST FORWARD regimen shall be employed. If boost is indicated, it shall be given either simultaneously using 48 Gy in 15 fractions as per RTOG 1005 (ClinicalTrials.gov identifier NCT01349322) or sequentially as $10.5 \mathrm{~Gy}$ in three fractions. During DORSCON Red, WBI or PMRT using 26 Gy in five fractions (FAST Trialists Group 2011) shall be used.

Node positive breast cancer Patients with N1 disease shall either be given either adjuvant RT to the breast/chest wall and ipsilateral supraclavicular fossa (and axilla, as indicated) using standard hypofractionation $40 \mathrm{~Gy}$ in 15 fractions (Haviland et al. 2013) or 26 Gy in five fractions (FAST Trialists Group 2011).

Adjuvant RT to the internal mammary nodal chain for patients with $\mathrm{N} 2$ disease shall be delivered using standard hypofractionation 40 Gy in 15 fractions (Haviland et al. 2013).

When indicated, boost shall be given either simultaneously using 48 Gy in 15 fractions or sequentially $10.5 \mathrm{~Gy}$ in three fractions.

During DORSCON Red, we recommend adjuvant RT using 26 Gy in five fractions (FAST Trialists Group 2011). Strict compliance to the organ-at-risk constraint should be observed (Brunt et al. 2020) and treatment should be delivered using free breath hold, with daily image guidance and using conformal techniques, for example, helical therapy for cardiac sparing.

\section{(ii) Palliative RT}

For patients with cord compression or bony metastases, we recommend RT using either 20 Gy in five fractions or single-fraction 8 or 10 Gy (Hoskin et al. 2019). In addition, for breast palliation, RT should be given weekly 6 Gy fractions for 5 to 6 weeks.

In patients with brain metastases, stereotactic radiosurgery shall be given following standard indications. Otherwise, whole brain RT shall be given using 20 Gy in five fractions or $12 \mathrm{~Gy}$ in two fractions daily.

During DORSCON Red, palliative RT should be administered over the least number of fractions possible.

\section{Palliative and supportive care}

Breast cancer patients encounter many adversities and have unmet needs. Besides having to cope with treatment side effects such as fatigue, nausea and pain, these patients have psychological and informational needs that often remain unmet (Fiszer et al. 2014). This struggle is exacerbated by the COVID-19 pandemic. Many patients report the COVID-19 pandemic as a major stressor, fuelling worries about the future and fears of getting infected during cancer treatment. Those who receive in-person emotional and information support from supportive care clinics find themselves bereft of such resources due to decreased nonessential clinic visits. To continue meeting supportive care needs within a pandemic situation, telemedicine solutions may be a possible avenue to enable continual care delivery yet maintain restrictive safety measures. Medications can be supplied via courier systems and titration done via symptom diaries and phone follow-up. Providing additional communication channels such as phone lines or emails manned by trained supportive care nurses are also viable options.

The untimely decision to hold or discontinue palliative SACT in the midst of a pandemic can be devastating to a patient with terminal breast cancer, misconstrued as 'giving up' or even fracture rapport and trust between the oncologist and the patient. Thus, discussions about goals of care between oncologists and patients are imperative (Ueda et al. 2020). Focusing future care plans on 'what matters most' for the individual patient against the background of the COVID-19 pandemic can help facilitate decision-making during this period of uncertainty.

The COVID-19 pandemic also poses difficulties to the care of cancer patients in the community. As cancer centres start reducing non-essential clinic visits and admissions, patients who no longer benefit from active oncological treatment will be referred to home hospice services to continue care within the community. These are also the frailer patients at higher risk of contracting and dying from COVID-19. A likely surge in referrals can easily overwhelm most hospice services that are already functioning at capacity. Moreover, as community spread of SARS-CoV-2 intensifies, the safety of home hospice personnel needs to be addressed, for instance when called to attend to terminally ill patients with fevers and/or chest infections at home. Home hospice services require adequate PPE and manpower to function at the frontline of continuing cancer care within the community.

The outbreak's impact is amplified at the end of life. Stringent hospital visitor policies aggravate the isolation of hospitalised cancer patients at their most vulnerable, while quarantine orders and social distancing policies can end up preventing loved ones from visiting even in the last weeks or days of life. Such isolation can lead to a sense of powerlessness, helplessness and frustration, 
Table 4 Recommendations for radiotherapy of breast cancers according to DORSCON status.

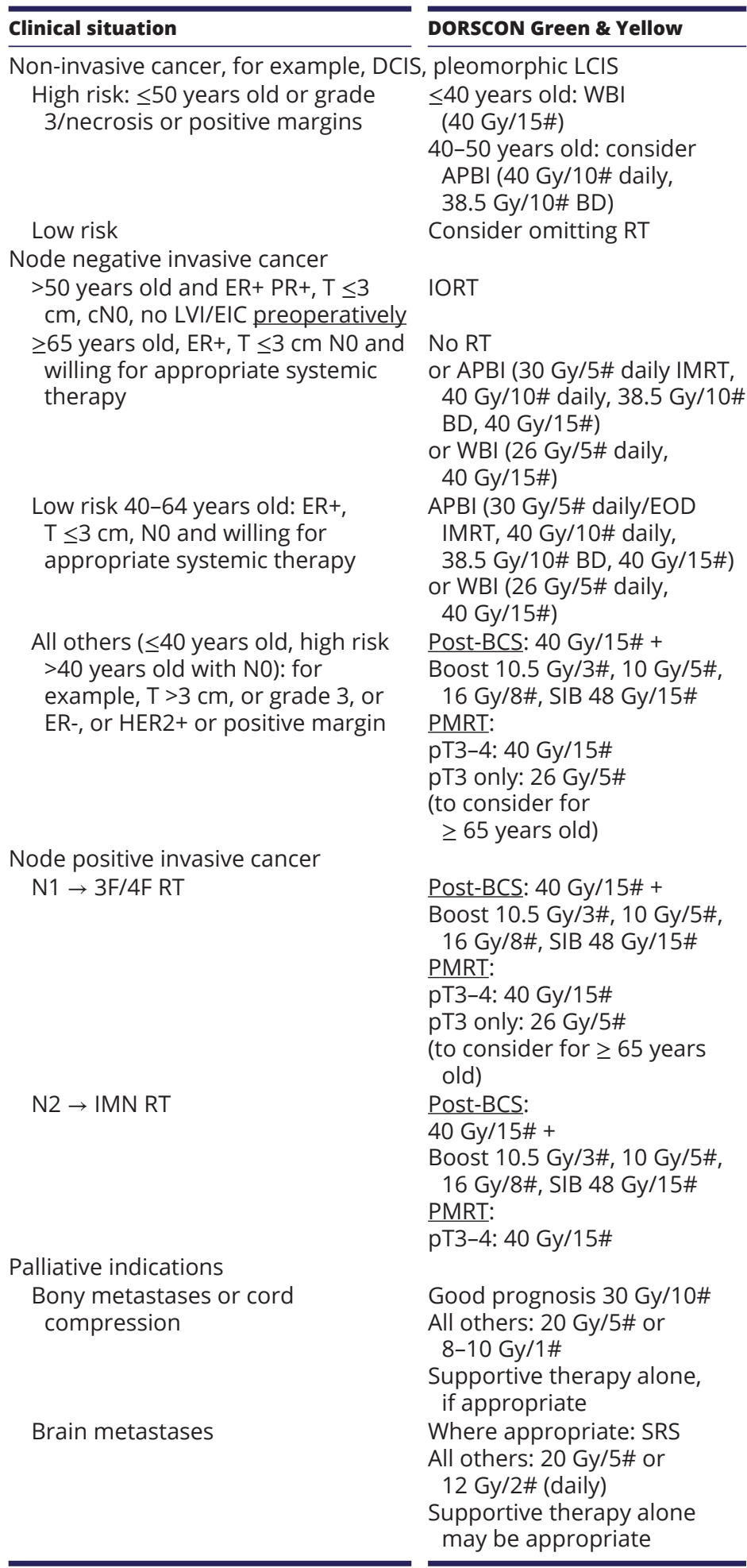

DORSCON Orange
APBI (30 Gy/5\# IMRT)
or WBI (26 Gy/5\#)

No RT No RT

$\begin{array}{ll}\text { IORT IORT } & \end{array}$

No RT No RT

APBI (30 Gy/5\# daily IMRT) or WBI 26 Gy/5\# daily (most cases), 40 Gy/15\# if cardiac dose is a concern

Post-BCS/PMRT: 26 Gy/5\# daily (most cases) or 40 Gy/15\# if cardiac dose is a concern

Post-BCS/PMRT: 26 Gy/5\# daily (most cases) or $40 \mathrm{~Gy} / 15 \#$ if cardiac dose is a concern

Post-BCS/PMRT: 26 Gy/5\# daily (most cases) or 40 Gy/15\# if cardiac dose is a concern

\section{8-10 Gy/1\# \\ or $20 \mathrm{~Gy} / 5 \#$ \\ or supportive therapy alone, if appropriate}

Where appropriate: SRS All others: 12 Gy/2\# (daily) or 20 Gy/5\#

Supportive therapy alone may be appropriate
No RT

APBI (30 Gy/5\# daily IMRT) or WBI (26 Gy/5\#)

Post-BCS + PMRT: 26 Gy/5\#

Post-BCS + PMRT: 26 Gy/5\#

\section{Post-BCS/PMRT: 26 Gy/5\# (note OAR guidelines)}

\section{8-10 Gy/1\# \\ or supportive therapy \\ alone, if appropriate}

Supportive therapy alone or $12 \mathrm{~Gy} / 2 \#$ (daily)

\#, fraction; 3F, three-field RT (breast/chest wall, supraclavicular fossa); 4F, four-field RT (breast/chest wall, supraclavicular fossa, axilla); APBI, accelerated partial breast irradiation; BCS, breast conserving surgery; BD, twice daily; DCIS, ductal carcinoma in situ; DORSCON, Disease Outbreak Response System Condition; EIC, extensive intraductal component; EOD, every other day; ER, oestrogen receptor; Gy, Grays; HER2, human EGF receptor 2; IMN, internal mammary nodal chain; IMRT, intensity-modulated RT; IORT, intraoperative radiotherapy; LCIS, lobular carcinoma in situ; LVI, lymphovascular invasion; OAR, organ at risk; PMRT, post-mastectomy RT; PR, progesterone receptor; RT, radiotherapy; SIB, simultaneous integrated boost; SRS, stereotactic radiosurgery; $\mathrm{T}$, tumour size; $\mathrm{WBI}$, whole breast irradiation.

https://erc.bioscientifica.com https://doi.org/10.1530/ERC-20-0157 (c) 2020 Society for Endocrinology Published by Bioscientifica Ltd. Printed in Great Britain 
with disruption of connectedness to self and also to family (Leong et al. 2004). Moreover, current rules to limit gatherings and truncate traditional death rituals can also disrupt bereavement by the family. Palliative care professionals should be cognisant of such issues and work proactively to mitigate them within the constraints of pandemic control. For instance, patients and their families can be encouraged to connect with one another via video phone calls or letter writing. Psychosocial and spiritual support for patients and families can be established using telehealth interventions, while patients can be taught to engage in meditation, mindfulness or yoga at home as coping mechanisms.

The COVID-19 outbreak is truly a threat to the field of palliative care. However, innovative solutions coupled with a mindset to never stop advocating for the patient, while paying heed to the need to protect society at large, will allow us to surmount this crisis.

\section{The Singapore experience compared to the rest of the world}

How breast cancer management in each country or healthcare system adapts to the COVID-19 pandemic depends on the local epidemiological situation and implemented outbreak response measures as well as the availability and organisation of resources and specialist manpower. While specific strategies may differ, common themes revolve around patient triage and care prioritisation, minimising hospital visits and adopting telemedicine, and modifying treatment plans to acceptable alternatives (Çakmak \& Özmen 2020, Dietz et al. 2020, Ismaili \& El Majjaoui 2020, Liu et al. 2020). The European approach is similar to ours in that recommendations for practice adaptation are layered upon the epidemiological phases of the outbreak which are coincidentally also classified as four tiers (Curigliano et al. 2020). Singapore is a small citystate with cancer centres being embedded within general hospitals or a wider hospital campus, augmenting the complexities of segregating cancer patients from suspected or confirmed cases of SARS-CoV-2 infection. Solutions such as designating 'COVID-19 free' oncological hubs can be useful in the European epicentre of the outbreak but are not applicable to Singapore (Viale et al. 2020).

\section{Conclusions}

In the throes of the COVID-19 pandemic, health systems are under immense strain and standard clinical practice has been disrupted globally. We depicted how elevating levels of epidemic response efforts in Singapore have affected the surgical, systemic and radiation treatments as well as palliative and support care of breast cancers. We also recommended prioritisation by clinical indication and practice modifications so as to marshal restricted resources for patient-centric care delivery without compromise to oncological outcomes. As the pandemic rapidly evolves, we recognise that our recommendations may need to be revised based on situational requirements. We strongly encourage clinicians to discuss the management of challenging or 'outlier' cases at tumour boards, especially if the prevailing circumstances dictate a deviation from standard practice or a prolonged delay to intended treatments.

The comprehensive, collaborative and multidisciplinary scope of our guidance can serve as a template for adaptations to clinical management in other tumour types during this pandemic or as a resource for breast oncology in future contingencies. The local contextualisation of the specific recommendations limits their generalisability to more resource-challenged healthcare settings during the COVID-19 epidemic. Nevertheless, the overarching principles underpinning our suggested conceptual framework are universally relevant and may be applied to pandemic planning guideline development in other parts of the world.

We anticipate a backlog of deferred cases and surge in new case referrals to breast oncologists when the pandemic eases. Just as our practices have become more focused with worsening outbreak severity, the transition back to conventional norms can be phased according to de-escalating DORSCON levels, applying the same standards of clinical priority but also considering the latest clinical status and the deferment period of diagnostic or therapeutic procedure in every patient.

Lastly, we recommend that breast cancer patients whose oncological care was modified from conventional standards during the COVID-19 outbreak be followed up for long-term outcomes. Doing so as part of clinical audits or observational studies will reveal the true impact of this pandemic on our patients and better prepare the breast oncology community to adapt our practice in response to another global health crisis

\section{Declaration of interest}

Jack Junjie Chan - Honoraria: Pfizer, Merck Sharp \& Dohme, Eisai, AstraZeneca, Novartis; Consulting or Advisory Role: Pfizer; Research Funding: OncoQuest, Bristol-Myers Squibb; Travel, Accommodations, Expenses: AstraZeneca, Pfizer, Celgene. Joline Si Jing Lim - Honoraria: Pfizer, Novartis; Research Funding: Synthon; Travel, Accommodations, 
Expenses: Novartis, Pfizer, AstraZeneca. Tira Jing Ying Tan - Consulting or Advisory Role: Roche, Novartis, Eli Lilly; Research Funding: AstraZeneca; Travel, Accommodations, Expenses: AstraZeneca, Eisai. The other authors have nothing to disclose.

\section{Funding}

This work was not supported by any specific grant from any funding agency in the public, commercial or not-for-profit sectors.

\section{Author contribution statement}

Jack Junjie Chan and Jing Ying Tan performed conception and design, selection of notable articles for review, critical review of the literature, composition of the manuscript and final approval. Sim Yirong, Samuel Guan Wei Ow, Joline Si Jing Lim, Grace Kusumawidjaja, Qingyuan Zhuang, Ru Xin Wong, and Fuh Yong Wong performed selection of notable articles for review, critical review of the literature, composition of the manuscript and final approval. Veronique Kiak Mien Tan performed selection of notable articles for review, composition of the manuscript and final approval.

\section{Acknowledgements}

The authors acknowledge all medical and nursing staff who provided care for the patients at National Cancer Centre Singapore, National University Cancer Institute, Singapore, and Singapore General Hospital and colleagues in their respective departments who contributed to the drawing up of institutional practice guidelines during the COVID-19 outbreak.

\section{References}

André F, Ciruelos E, Rubovszky G, Campone M, Loibl S, Rugo HS, Iwata H, Conte P, Mayer IA, Kaufman B, et al. 2019 Alpelisib for PIK3CA-mutated, hormone receptor-positive advanced breast cancer. New England Journal of Medicine 380 1929-1940. (https://doi. org/10.1056/NEJMoa1813904)

Barellini L, Marcasciano M, Lo Torto F, Fausto A, Ribuffo D \& Casella D 2019 Intraoperative ultrasound and oncoplastic combined approach: an additional tool for the oncoplastic surgeon to obtain tumor-free margins in breast conservative surgery - a 2-year single-center prospective study. Clinical Breast Cancer 202020 E290-E294. (https:// doi.org/10.1016/j.clbc.2019.10.004)

Braunstein LZ, Thor M, Flynn J, Cost Z, Wilgucki M, Rosenbaum S, Zhang Z, Gillespie E, McCormick B, Khan A, et al. 2019 Daily fractionation of external beam accelerated partial breast irradiation to $40 \mathrm{~Gy}$ is well tolerated and locally effective. International Journal of Radiation Oncology, Biology, Physics 104 859-866. (https://doi. org/10.1016/j.ijrobp.2019.02.050)

Brunt M, Chakraborty S, Chatterjee S, Cleator S, Coles C, Kirby A, Somaiah N \& Yarnold J 2020 Emergency guideline for treating patients requiring adjuvant internal mammary chain radiotherapy in 5 fractions during COVID-19 pandemic. London, UK: The Royal College of Radiologists. (available at: https://www.rcr.ac.uk/sites/ default/files/breast-cancer-imc-treatment-5-fraction-covid19.pdf)

Çakmak GK \& Özmen V 2020 Sars-CoV-2 (COVID-19) outbreak and breast cancer surgery in Turkey. European Journal of Breast Health 16 83-85. (https://doi.org/10.5152/ejbh.2020.300320)

Cardoso F, Senkus E, Costa A, Papadopoulos E, Aapro M, André F, Harbeck N, Aguilar Lopez B, Barrios CH, Bergh J, et al. 2018 4th ESO-ESMO international consensus guidelines for advanced breast cancer (ABC 4). Annals of Oncology 29 1634-1657. (https://doi. org/10.1093/annonc/mdy192)

Cardoso F, Kyriakides S, Ohno S, Penault-Llorca F, Poortmans P, Rubio IT, Zackrisson S, Senkus E \& ESMO Guidelines Committee 2019 Early breast cancer: ESMO Clinical Practice Guidelines for diagnosis, treatment and follow-up. Annals of Oncology 30 1194-1220. (https:// doi.org/10.1093/annonc/mdz173)

Chew MH, Koh FH \& Ng KH 2020 A call to arms: a perspective of safe general surgery in Singapore during the COVID-19 pandemic. Singapore Medical Journal [epub]. (https://doi.org/10.11622/smedj.2020049)

Coles CE, Griffin CL, Kirby AM, Titley J, Agrawal RK, Alhasso A, Bhattacharya IS, Brunt AM, Ciurlionis L, Chan C, et al. 2017 Partialbreast radiotherapy after breast conservation surgery for patients with early breast cancer (UK IMPORT LOW trial): 5 -year results from a multicentre, randomised, controlled, phase 3, non-inferiority trial. Lancet 390 1048-1060. (https://doi.org/10.1016/S01406736(17)31145-5)

Cortazar P, Zhang L, Untch M, Mehta K, Costantino JP, Wolmark N, Bonnefoi H, Cameron D, Gianni L, Valagussa P, et al. 2014 Pathological complete response and long-term clinical benefit in breast cancer: the CTNeoBC pooled analysis. Lancet 384 164-172. (https://doi.org/10.1016/S0140-6736(13)62422-8)

Cortés J, O'Shaughnessy J, Loesch D, Blum JL, Vahdat LT, Petrakova K, Chollet P, Manikas A, Diéras V, Delozier T, et al. 2011 Eribulin monotherapy versus treatment of physician's choice in patients with metastatic breast cancer (EMBRACE): a phase 3 open-label randomised study. Lancet 377 914-923. (https://doi.org/10.1016/ S0140-6736(11)60070-6)

Curigliano G, Cardoso MJ, Poortmans P, Gentilini O, Pravettoni G, Mazzocco K, Houssami N, Pagani O, Senkus E, Cardoso F, et al. 2020 Recommendations for triage, prioritization and treatment of breast cancer patients during the COVID-19 pandemic. Breast 52 8-16. (https://doi.org/10.1016/j.breast.2020.04.006)

Cuzick J, Sestak I, Pinder SE, Ellis IO, Forsyth S, Bundred NJ, Forbes JF, Bishop H, Fentiman IS \& George WD 2011 Effect of tamoxifen and radiotherapy in women with locally excised ductal carcinoma in situ: long-term results from the UK/ANZ DCIS trial. Lancet Oncology 12 21-29. (https://doi.org/10.1016/S1470-2045(10)70266-7)

Diéras V, Miles D, Verma S, Pegram M, Welslau M, Baselga J, Krop IE, Blackwell K, Hoersch S, Xu J, et al. 2017 Trastuzumab emtansine versus capecitabine plus lapatinib in patients with previously treated HER2-positive advanced breast cancer (EMILIA): a descriptive analysis of final overall survival results from a randomised, openlabel, phase 3 trial. Lancet Oncology 18 732-742. (https://doi. org/10.1016/S1470-2045(17)30312-1)

Dietz JR, Moran MS, Isakoff SJ, Kurtzman SH, Willey SC, Burstein HJ, Bleicher RJ, Lyons JA, Sarantou T, Baron PL, et al. 2020 Recommendations for prioritization, treatment and triage of breast cancer patients during the COVID-19 pandemic. Columbia, MD, USA: The American Society of Breast Surgeons. (available at: https:// www.breastsurgeons.org/docs/statements/ASBrS\%20NAPBC\%20 COC\%20NCCN\%20ACR\%20BC\%20Covid\%20MANUSCRIPT\%20 BCRT\%20Rev1-4_7_2020\%20_1022amEST.pdf)

Dupont E, Tsangaris T, Garcia-Cantu C, Howard-McNatt M, Chiba A, Berger AC, Levine EA, Gass JS, Gallagher K, Lum SS, et al. 2019 Resection of cavity shave margins in stage 0 -III breast cancer patients undergoing breast conserving surgery: a prospective multicenter randomized controlled trial. Annals of Surgery [epub]. (https://doi. org/10.1097/SLA.0000000000003449)

Earl HM, Hiller L, Vallier AL, Loi S, McAdam K, Hughes-Davies L, Harnett AN, Ah-See ML, Simcock R, Rea D, et al. 20196 versus 12 months of adjuvant trastuzumab for HER2-positive early breast cancer (PERSEPHONE): 4-year disease-free survival results of a randomised phase 3 non-inferiority trial. Lancet 393 2599-2612. (https://doi.org/10.1016/S0140-6736(19)30650-6) 
FAST Trialists Group, Agrawal RK, Alhasso A, Barrett-Lee PJ, Bliss JM, Bliss P, Bloomfield D, Bowen J, Brunt AM, Donovan E, et al. 2011 First results of the randomised UK FAST trial of radiotherapy hypofractionation for treatment of early breast cancer (CRUKE/04/015). Radiotherapy and Oncology 100 93-100. (https://doi. org/10.1016/j.radonc.2011.06.026)

Fedele P, Marino A, Orlando L, Schiavone P, Nacci A, Sponziello F, Rizzo P, Calvani N, Mazzoni E, Cinefra M, et al. 2012 Efficacy and safety of low-dose metronomic chemotherapy with capecitabine in heavily pretreated patients with metastatic breast cancer. European Journal of Cancer 48 24-29. (https://doi.org/10.1016/j.ejca.2011.06.040)

Fiszer C, Dolbeault S, Sultan S \& Bredart A 2014 Prevalence, intensity, and predictors of the supportive care needs of women diagnosed with breast cancer: a systematic review. Psycho-Oncology 23 361-374. (https://doi.org/10.1002/pon.3432)

Francis PA, Pagani O, Fleming GF, Walley BA, Colleoni M, Láng I, Gómez HL, Tondini C, Ciruelos E, Burstein HJ, et al. 2018 Tailoring adjuvant endocrine therapy for premenopausal breast cancer. New England Journal of Medicine 379 122-137. (https://doi.org/10.1056/ NEJMoa1803164)

Gianni L, Eiermann W, Semiglazov V, Lluch A, Tjulandin S, Zambetti M, Moliterni A, Vazquez F, Byakhov MJ, Lichinitser M, et al. 2014 Neoadjuvant and adjuvant trastuzumab in patients with HER2positive locally advanced breast cancer (NOAH): follow-up of a randomised controlled superiority trial with a parallel HER2-negative cohort. Lancet Oncology 15 640-647. (https://doi.org/10.1016/S14702045(14)70080-4)

Gianni L, Pienkowski T, Im YH, Tseng LM, Liu MC, Lluch A, Staroslawska E, De La Haba-Rodriguez J, Im SA, Pedrini JL, et al. 2016 5 -year analysis of neoadjuvant pertuzumab and trastuzumab in patients with locally advanced, inflammatory, or early-stage HER2positive breast cancer (NeoSphere): a multicentre, open-label, phase 2 randomised trial. Lancet Oncology 17 791-800. (https://doi. org/10.1016/S1470-2045(16)00163-7)

Gligorov J, Ataseven B, Verrill M, De Laurentiis M, Jung KH, Azim HA, Al-Sakaff N, Lauer S, Shing M, Pivot X, et al. 2017 Safety and tolerability of subcutaneous trastuzumab for the adjuvant treatment of human epidermal growth factor receptor 2-positive early breast cancer: SafeHer phase III study's primary analysis of 2573 patients. European Journal of Cancer 82 237-246. (https://doi.org/10.1016/j.ejca.2017.05.010)

Hanna TP, Evans GA \& Booth CM 2020 Cancer, COVID-19 and the precautionary principle: prioritizing treatment during a global pandemic. Nature Reviews: Clinical Oncology 17 268-270. (https://doi. org/10.1038/s41571-020-0362-6)

Haviland JS, Owen JR, Dewar JA, Agrawal RK, Barrett J, Barrett-Lee PJ, Dobbs HJ, Hopwood P, Lawton PA, Magee BJ, et al. 2013 The UK Standardisation of Breast Radiotherapy (START) trials of radiotherapy hypofractionation for treatment of early breast cancer: 10-year follow-up results of two randomised controlled trials. Lancet:Oncology 14 1086-1094. (https://doi.org/10.1016/S14702045(13)70386-3)

Hoskin PJ, Hopkins K, Misra V, Holt T, McMenemin R, Dubois D, McKinna F, Foran B, Madhavan K, MacGregor C, et al. 2019 Effect of single-fraction vs multifraction radiotherapy on ambulatory status among patients with spinal canal compression from metastatic cancer: the SCORAD randomized clinical trial. JAMA 322 2084-2094. (https://doi.org/10.1001/jama.2019.17913)

Huober J, Fasching PA, Barsoum M, Petruzelka L, Wallwiener D, Thomssen C, Reimer T, Paepke S, Azim HA, Ragosch V, et al. 2012 Higher efficacy of letrozole in combination with trastuzumab compared to letrozole monotherapy as first-line treatment in patients with HER2-positive, hormone-receptor-positive metastatic breast cancer - results of the eLEcTRA trial. Breast 21 27-33. (https:// doi.org/10.1016/j.breast.2011.07.006)

Hwang ES, Hyslop T, Hendrix LH, Duong S, Bedrosian I, Price E, Caudle A, Hieken T, Guenther J, Hudis CA, et al. 2020 Phase II single-arm study of preoperative letrozole for estrogen receptorpositive postmenopausal ductal carcinoma in situ: CALGB 40903 (Alliance). Journal of Clinical Oncology 38 1284-1292. (https://doi. org/10.1200/JCO.19.00510)

Ismaili N \& El Majjaoui S 2020 Management of breast cancer during COVID-19 pandemic in Morocco. Breast Journal [epub]. (https://doi. org/10.1111/tbj.13925)

Jackisch C, Kim SB, Semiglazov V, Melichar B, Pivot X, Hillenbach C, Stroyakovskiy D, Lum BL, Elliott R, Weber HA, et al. 2015 Subcutaneous versus intravenous formulation of trastuzumab for HER2-positive early breast cancer: updated results from the phase III HannaH study. Annals of Oncology 26 320-325. (https://doi. org/10.1093/annonc/mdu524)

Jones S, Holmes FA, O'Shaughnessy J, Blum JL, Vukelja SJ, McIntyre KJ, Pippen JE, Bordelon JH, Kirby RL, Sandbach J, et al. 2009 Docetaxel with cyclophosphamide is associated with an overall survival benefit compared with doxorubicin and cyclophosphamide: 7-year follow-up of US Oncology Research trial 9735. Journal of Clinical Oncology 27 1177-1183. (https://doi. org/10.1200/JCO.2008.18.4028)

Jones SE, Collea R, Paul D, Sedlacek S, Favret AM, Gore Jr I, Lindquist DL, Holmes FA, Allison MAK, Brooks BD, et al. 2013 Adjuvant docetaxel and cyclophosphamide plus trastuzumab in patients with HER2-amplified early stage breast cancer: a singlegroup, open-label, phase 2 study. Lancet Oncology 14 1121-1128. (https://doi.org/10.1016/S1470-2045(13)70384-X)

Kaufman B, Mackey JR, Clemens MR, Bapsy PP, Vaid A, Wardley A, Tjulandin S, Jahn M, Lehle M, Feyereislova A, et al. 2009 Trastuzumab plus anastrozole versus anastrozole alone for the treatment of postmenopausal women with human epidermal growth factor receptor 2-positive, hormone receptor-positive metastatic breast cancer: results from the randomized phase III TAnDEM study. Journal of Clinical Oncology 27 5529-5537. (https://doi.org/10.1200/ JCO.2008.20.6847)

Krop IE, Kim SB, Martin AG, LoRusso PM, Ferrero JM, BadovinacCrnjevic T, Hoersch S, Smitt M \& Wildiers H 2017 Trastuzumab emtansine versus treatment of physician's choice in patients with previously treated HER2-positive metastatic breast cancer (TH3RESA): final overall survival results from a randomised open-label phase 3 trial. Lancet Oncology 18 743-754. (https://doi.org/10.1016/S14702045(17)30313-3)

Kunkler IH, Williams LJ, Jack WJ, Cameron DA, Dixon JM \& PRIME II Investigators 2015 Breast-conserving surgery with or without irradiation in women aged 65 years or older with early breast cancer (PRIME II): a randomised controlled trial. Lancet Oncology 16 266-273. (https://doi.org/10.1016/S1470-2045(14)71221-5)

Lee CCM, Thampi S, Lewin B, Lim TJD, Rippin B, Wong WH \& Agrawal RV 2020 Battling COVID-19: critical care and peri-operative healthcare resource management strategies in a tertiary academic medical centre in Singapore. Anaesthesia 75 861-871. (https://doi. org/10.1111/anae.15074)

Lei S, Fang J, Sua W, Chen C, Chen J, Mei W, Zhan LY, Jia Y, Zhang L, Liu D, et al. 2020 Clinical characteristics and outcomes of patients undergoing surgeries during the incubation period of COVID-19 infection. EClinicalMedicine 21 100331. (https://doi.org/10.1016/j. eclinm.2020.100331)

Leong IY, Lee AO, Ng TW, Lee LB, Koh NY, Yap E, Guay S \& Ng LM 2004 The challenge of providing holistic care in a viral epidemic: opportunities for palliative care. Palliative Medicine 18 12-18. (https://doi.org/10.1191/0269216304pm859oa)

Liang W, Guan W, Chen R, Wang W, Li J, Xu K, Li C, Ai Q, Lu W, Liang H, et al. 2020 Cancer patients in SARS-CoV-2 infection: a nationwide analysis in China. Lancet Oncology 21 335-337. (https:// doi.org/10.1016/S1470-2045(20)30096-6)

Liu BL, Ma F, Wang JN, Fan Y, Mo HN \& Xu BH 2020 Health management of breast cancer patients outside the hospital during (c) 2020 Society for Endocrinology Published by Bioscientifica Ltd. Printed in Great Britain 
the outbreak of 2019 novel coronavirus disease. Zhonghua Zhong Liu Za Zhi 42 288-291. (https://doi.org/10.3760/ cma.j.cn112152-20200221-00110)

Livi L, Meattini I, Marrazzo L, Simontacchi G, Pallotta S, Saieva C, Paiar F, Scotti V, De Luca Cardillo C, Bastiani P, et al. 2015 Accelerated partial breast irradiation using intensity-modulated radiotherapy versus whole breast irradiation: 5-year survival analysis of a phase 3 randomised controlled trial. European Journal of Cancer 51 451-463. (https://doi.org/10.1016/j.ejca.2014.12.013)

Ma SJ, Oladeru OT \& Singh AK 2020 Association of survival with chemoendocrine therapy in women with small, hormone receptorpositive, ERBB2-positive, node-negative breast cancer. JAMA Network Open 3 e202507. (https://doi.org/10.1001/ jamanetworkopen.2020.2507)

Masuda N, Lee SJ, Ohtani S, Im YH, Lee ES, Yokota I, Kuroi K, Im SA, Park BW, Kim SB, et al. 2017 Adjuvant capecitabine for breast cancer after preoperative chemotherapy. New England Journal of Medicine 376 2147-2159. (https://doi.org/10.1056/NEJMoa1612645)

Masuda N, Sagara Y, Kinoshita T, Iwata H, Nakamura S, Yanagita Y, Nishimura R, Iwase H, Kamigaki S, Takei H, et al. 2012 Neoadjuvant anastrozole versus tamoxifen in patients receiving goserelin for premenopausal breast cancer (STAGE): a double-blind, randomised phase 3 trial. Lancet Oncology 13 345-352. (https://doi.org/10.1016/ S1470-2045(11)70373-4)

McCormick JT, Keleher AJ, Tikhomirov VB, Budway RJ \& Caushaj PF 2004 Analysis of the use of specimen mammography in breast conservation therapy. American Journal of Surgery 188 433-436. (https://doi.org/10.1016/j.amjsurg.2004.06.030)

Mehta P, McAuley DF, Brown M, Sanchez E, Tattersall RS, Manson JJ \& HLH Across Speciality Collaboration, UK 2020 COVID-19: consider cytokine storm syndromes and immunosuppression. Lancet 395 1033-1034. (https://doi.org/10.1016/S0140-6736(20)30628-0)

Ministry of Health, Singapore $2014 \mathrm{MOH}$ pandemic readiness and response plan for influenza and other acute respiratory diseases (revised April 2014). Singapore: Ministry of Health, Singapore. (available at: https://www.moh.gov.sg/docs/librariesprovider5/ diseases-updates/interim-pandemic-plan-public-ver-_april-2014.pdf)

Munzone E \& Colleoni M 2015 Clinical overview of metronomic chemotherapy in breast cancer. Nature Reviews: Clinical Oncology 12 631-644. (https://doi.org/10.1038/nrclinonc.2015.131)

Ng Y, Li Z, Chua YX, Chaw WL, Zhao Z, Er B, Pung R, Chiew CJ, Lye DC, Heng D, et al. 2020 Evaluation of the effectiveness of surveillance and containment measures for the first 100 patients with COVID-19 in Singapore - January 2-February 29, 2020. Morbidity and Mortality Weekly Report 69 307-311. (https://doi. org/10.15585/mmwr.mm6911e1)

Ngoi N, Lim J, Ow S, Jen WY, Lee M, Teo W, Ho J, Sundar R, Tung ML, Lee YM, et al. 2020 A segregated-team model to maintain cancer care during the COVID-19 outbreak at an academic center in Singapore. Annals of Oncology 31 840-843. (https://doi.org/10.1016/j. annonc.2020.03.306)

Pentheroudakis G, Jordan K, Lordick F, Douillard JY \& Peters S 2020 What should medical oncologists know about COVID-19? Lugano, Switzerland: European Society for Medical Oncology. (available at: https://www.esmo.org/covid-19-and-cancer/q-a-on-covid-19)

Perez EA, Barrios C, Eiermann W, Toi M, Im Y-H, Conte P, Martin M, Pienkowski T, Pivot X, Burris HA, et al. 2017 Trastuzumab emtansine with or without pertuzumab versus trastuzumab plus taxane for human epidermal growth factor receptor 2-positive, advanced breast cancer: primary results from the phase III MARIANNE study. Journal of Clinical Oncology 35 141-148. (https://doi.org/10.1200/ JCO.2016.67.4887)

Piccart M, Hortobagyi GN, Campone M, Pritchard KI, Lebrun F, Ito Y, Noguchi S, Perez A, Rugo HS, Deleu I, et al. 2014 Everolimus plus exemestane for hormone-receptor-positive, human epidermal growth factor receptor-2-negative advanced breast cancer: overall survival results from BOLERO-2. Annals of Oncology 25 2357-2362. (https:// doi.org/10.1093/annonc/mdu456)

Pivot X, Spano JP, Espie M, Cottu P, Jouannaud C, Pottier V, Moreau L, Extra JM, Lortholary A, Rivera P, et al. 2017 Patients' preference of trastuzumab administration (subcutaneous versus intravenous) in HER2-positive metastatic breast cancer: results of the randomised MetaspHer study. European Journal of Cancer 82 230-236. (https://doi. org/10.1016/j.ejca.2017.05.009)

Robson M, Im SA, Senkus E, Xu B, Domchek SM, Masuda N, Delaloge S, Li W, Tung N, Armstrong A, et al. 2017 Olaparib for metastatic breast cancer in patients with a germline BRCA mutation. New England Journal of Medicine 377 523-533. (https://doi.org/10.1056/NEJMoa1706450)

Schmid P, Adams S, Rugo HS, Schneeweiss A, Barrios CH, Iwata H, Diéras V, Hegg R, Im SA, Shaw Wright G, et al. 2018 Atezolizumab and nab-paclitaxel in advanced triple-negative breast cancer. New England Journal of Medicine 379 2108-2121. (https://doi.org/10.1056/ NEJMoa1809615)

Schneeweiss A, Chia S, Hickish T, Harvey V, Eniu A, Hegg R, Tausch C, Seo JH, Tsai YF, Ratnayake J, et al. 2013 Pertuzumab plus trastuzumab in combination with standard neoadjuvant anthracycline-containing and anthracycline-free chemotherapy regimens in patients with HER2-positive early breast cancer: a randomized phase II cardiac safety study (TRYPHAENA). Annals of Oncology 24 2278-2284. (https://doi.org/10.1093/annonc/mdt182)

Smith IE, Dowsett M, Ebbs SR, Dixon JM, Skene A, Blohmer JU, Ashley SE, Francis S, Boeddinghaus I, Walsh G, et al. 2005 Neoadjuvant treatment of postmenopausal breast cancer with anastrozole, tamoxifen, or both in combination: the immediate preoperative anastrozole, tamoxifen, or combined with tamoxifen (IMPACT) multicenter double-blind randomized trial. Journal of Clinical Oncology 23 5108-5116. (https:// doi.org/10.1200/JCO.2005.04.005)

Sparano JA, Gray RJ, Makower DF, Pritchard KI, Albain KS, Hayes DF, Geyer Jr CE, Dees EC, Goetz MP, Olson Jr JA, et al. 2018 Adjuvant chemotherapy guided by a 21-gene expression assay in breast cancer. New England Journal of Medicine 379 111-121. (https://doi. org/10.1056/NEJMoa1804710)

Spring LM, Wander SA, André F, Moy B, Turner NC \& Bardia A 2020 Cyclin-dependent kinase 4 and 6 inhibitors for hormone receptorpositive breast cancer: past, present, and future. Lancet 395 817-827. (https://doi.org/10.1016/S0140-6736(20)30165-3)

Swain SM, Miles D, Kim SB, Im YH, Im SA, Semiglazov V, Ciruelos E, Schneeweiss A, Loi S, Monturus E, et al. 2020 Pertuzumab, trastuzumab, and docetaxel for HER2-positive metastatic breast cancer (Cleopatra): end-of-study results from a double-blind, randomised, placebo-controlled, phase 3 study. Lancet Oncology 21 519-530. (https://doi.org/10.1016/S1470-2045(19)30863-0)

Ti LK, Ang LS, Foong TW \& Ng BSW 2020 What we do when a COVID19 patient needs an operation: operating room preparation and guidance. Canadian Journal of Anaesthesia 67 756-758. (https://doi. org/10.1007/s12630-020-01617-4)

Tutt A, Tovey H, Cheang MCU, Kernaghan S, Kilburn L, Gazinska P, Owen J, Abraham J, Barrett S, Barrett-Lee P, et al. 2018 Carboplatin in BRCA1/2-mutated and triple-negative breast cancer BRCAness subgroups: the TNT Trial. Nature Medicine 24 628-637. (https://doi. org/10.1038/s41591-018-0009-7)

Ueda M, Martins R, Hendrie PC, McDonnell T, Crews JR, Wong TL, McCreery B, Jagels B, Crane A, Byrd DR, et al. 2020 Managing cancer care during the COVID-19 pandemic: agility and collaboration toward a common goal. Journal of the National Comprehensive Cancer Network [epub]. (https://doi.org/10.6004/jnccn.2020.7560)

Vaidya JS, Wenz F, Bulsara M, Tobias JS, Joseph DJ, Keshtgar M, Flyger HL, Massarut S, Alvarado M, Saunders C, et al. 2014 Riskadapted targeted intraoperative radiotherapy versus whole-breast radiotherapy for breast cancer: 5-year results for local control and overall survival from the TARGIT - a randomised trial. Lancet $\mathbf{3 8 3}$ 603-613. (https://doi.org/10.1016/S0140-6736(13)61950-9) https://erc.bioscientifica.com

https://doi.org/10.1530/ERC-20-0157 (c) 2020 Society for Endocrinology Published by Bioscientifica Ltd. Printed in Great Britain 
van Poznak C, Somerfield MR, Barlow WE, Biermann JS, Bosserman LD, Clemons MJ, Dhesy-Thind SK, Dillmon MS, Eisen A, Frank ES, et al. 2017 Role of bone-modifying agents in metastatic breast cancer: an American Society of Clinical Oncology-Cancer Care Ontario focused guideline update. Journal of Clinical Oncology 35 3978-3986. (https:// doi.org/10.1200/JCO.2017.75.4614)

Viale G, Licata L, Sica L, Zambelli S, Zucchinelli P, Rognone A, Aldrighetti D, Di Micco R, Zuber V, Pasetti M, et al. 2020 Personalized risk-benefit ratio adaptation of breast cancer care at the epicenter of COVID-19 outbreak. Oncologist [epub]. (https://doi. org/10.1634/theoncologist.2020-0316)

Vicini FA, Cecchini RS, White JR, Arthur DW, Julian TB, Rabinovitch RA, Kuske RR, Ganz PA, Parda DS, Scheier MF, et al. 2019 Long-term primary results of accelerated partial breast irradiation after breastconserving surgery for early-stage breast cancer: a randomised, phase 3, equivalence trial. Lancet 394 2155-2164. (https://doi.org/10.1016/ S0140-6736(19)32514-0)

von Minckwitz G, Procter M, de Azambuja E, Zardavas D, Benyunes M, Viale G, Suter T, Arahmani A, Rouchet N, Clark E, et al. 2017 Adjuvant pertuzumab and trastuzumab in early HER2-positive breast cancer. New England Journal of Medicine 377 122-131. (https://doi. org/10.1056/NEJMoa1703643)

von Minckwitz G, Huang CS, Mano MS, Loibl S, Mamounas EP, Untch M, Wolmark N, Rastogi P, Schneeweiss A, Redondo A, et al. 2019 Trastuzumab emtansine for residual invasive HER2-positive breast cancer. New England Journal of Medicine 380 617-628. (https:// doi.org/10.1056/NEJMoa1814017)
Whelan TJ, Julian JA, Berrang TS, Kim DH, Germain I, Nichol AM, Akra M, Lavertu S, Germain F, Fyles A, et al. 2019 External beam accelerated partial breast irradiation versus whole breast irradiation after breast conserving surgery in women with ductal carcinoma in situ and node-negative breast cancer (RAPID): a randomised controlled trial. Lancet 394 2165-2172. (https://doi.org/10.1016/ S0140-6736(19)32515-2)

Wong JEL, Leo YS \& Tan CC 2020 COVID-19 in Singapore - current experience: critical global issues that require attention and action. JAMA 323 1243-1244. (https://doi.org/10.1001/jama.2020.2467)

Yu J, Ouyang W, Chua MLK \& Xie C 2020 SARS-CoV-2 transmission in patients with cancer at a tertiary care hospital in Wuhan, China. JAMA Oncology [epub]. (https://doi.org/10.1001/jamaoncol.2020.0980)

Zhang L, Zhu F, Xie L, Wang C, Wang J, Chen R, Jia P, Guan HQ, Peng L, Chen Y, et al. 2020 Clinical characteristics of COVID-19infected cancer patients: a retrospective case study in three hospitals within Wuhan, China. Annals of Oncology 31 894-901. (https://doi. org/10.1016/j.annonc.2020.03.296)

Zhou F, Yu T, Du R, Fan G, Liu Y, Liu Z, Xiang J, Wang Y, Song B, Gu X, et al. 2020 Clinical course and risk factors for mortality of adult inpatients with COVID-19 in Wuhan, China: a retrospective cohort study. Lancet 395 1054-1062. (https://doi.org/10.1016/S01406736(20)30566-3)

Zhu N, Zhang D, Wang W, Li X, Yang B, Song J, Zhao X, Huang B, Shi W, Lu R, et al. 2020 A novel coronavirus from patients with pneumonia in China, 2019. New England Journal of Medicine 382 727-733. (https://doi.org/10.1056/NEJMoa2001017)

Received in final form 8 June 2020

Accepted 15 June 2020

Accepted Manuscript published online 16 June 2020 (c) 2020 Society for Endocrinology Published by Bioscientifica Ltd. Printed in Great Britain 